OPEN ACCESS

Edited by:

Sujogya Kumar Panda,

KU Leuven, Belgium

Reviewed by:

Murugan Kasi,

Manonmaniam Sundaranar University,

India

Fazlurrahman Khan

Sharda University, India

*Correspondence:

Rojita Mishra

rojitamishra@gmail.com

†These authors have contributed equally to this work and share first authorship

Specialty section:

This article was submitted to

Antimicrobials, Resistance

and Chemotherapy,

a section of the journal

Frontiers in Microbiology

Received: 27 May 2020

Accepted: 30 September 2020

Published: 29 October 2020

Citation:

Mishra R, Panda AK,

De Mandal S, Shakeel M, Bisht SS and Khan J (2020) Natural Anti-biofilm Agents: Strategies to Control Biofilm-Forming Pathogens. Front. Microbiol. 11:566325. doi: 10.3389/fmicb.2020.566325

\section{Natural Anti-biofilm Agents: Strategies to Control Biofilm-Forming Pathogens}

\author{
Rojita Mishra ${ }^{* \dagger}$, Amrita Kumari Panda ${ }^{2+}$, Surajit De Mandal ${ }^{3}$, Muhammad Shakeel ${ }^{3}$, \\ Satpal Singh Bisht ${ }^{4}$ and Junaid Khan ${ }^{5}$
}

\begin{abstract}
${ }^{1}$ Department of Botany, Polasara Science College, Polasara, India, ${ }^{2}$ Department of Biotechnology, Sant Gahira Guru University, Ambikapur, India, ${ }^{3}$ Key Laboratory of Bio-Pesticide Innovation and Application of Guangdong Province, College of Agriculture, South China Agricultural University, Guangzhou, China, ${ }^{4}$ Department of Zoology, Kumaun University, Nainital, India, ${ }^{5}$ Department of Pharmacy, Sant Gahira Guru University, Ambikapur, India
\end{abstract}

Pathogenic microorganisms and their chronic pathogenicity are significant concerns in biomedical research. Biofilm-linked persistent infections are not easy to treat due to resident multidrug-resistant microbes. Low efficiency of various treatments and in vivo toxicity of available antibiotics drive the researchers toward the discovery of many effective natural anti-biofilm agents. Natural extracts and natural product-based antibiofilm agents are more efficient than the chemically synthesized counterparts with lesser side effects. The present review primarily focuses on various natural anti-biofilm agents, i.e., phytochemicals, biosurfactants, antimicrobial peptides, and microbial enzymes along with their sources, mechanism of action via interfering in the quorum-sensing pathways, disruption of extracellular polymeric substance, adhesion mechanism, and their inhibitory concentrations existing in literature so far. This study provides a better understanding that a particular natural anti-biofilm molecule exhibits a different mode of actions and biofilm inhibitory activity against more than one pathogenic species. This information can be exploited further to improve the therapeutic strategy by a combination of more than one natural anti-biofilm compounds from diverse sources.

Keywords: microbial biofilm, therapeutic strategies, phytocompounds, multidrug resistance, antimicrobial peptides, biosurfactant

\section{BACKGROUND}

The antimicrobial tolerance of biofilms has emerged as a significant challenge to medical scientists across diverse healthcare sectors. Synthetic drugs, combinational therapy, and antibiotic hybrids could not achieve and deliver the desired results during the treatment. The hunt for novel antimicrobials in drug resistance emergency insists on the scientific society to search novel natural anti-biofilm agents. The focus of the present review is to revisit various natural products to overcome the biofilm-forming microorganisms and provide concise information on existing

Abbreviations: AHL, acyl-homoserine lactone; AMP, anti-microbial peptide; BFC, biofilm-forming capacity; CLSM, confocal laser scanning microscopy; CSH, cell surface hydrophobicity; eDNA, extracellular DNA; EPS, extracellular polymeric substances; GA, ginkgolic acid; HSL, homoserine lactone; MBIC, minimum biofilm inhibitory concentration; MFC, minimal fungicidal concentration; MIC, minimum inhibitory concentration; PMNs, polymorphonuclear leukocytes; QS, quorum sensing; SEM, scanning electron microscopy; TEM, transmission electron microscopy. 
confines and recent developments in the modification of different natural anti-biofilm agents to make them effective drug candidates for clinical exploitation.

\section{The Biofilms}

The concept of biofilm was first developed by Marshall et al. (1971) and further described by Fletcher, Characklis, and Costerton, "Biofilm is the unique pattern of growth in the life cycle of microbes that provides specific properties, advantages and higher level of organization to the free living bacterial cells during colonization" (Characklis, 1973; Fletcher and Floodgate, 1973; Geesey et al., 1978; Flemming and Wuertz, 2019). The description of biofilm is much more clarified by Flemming and Wuertz (2019) that biofilms are aggregates of microorganisms with distinct sessile cells followed by cell division to form small clusters, microcolonies, and larger sums. The film underneath the biofilm is only in direct contact with the substratum in a multilayered heterogeneous microbial mat. Biofilms are extensively used in various biotechnological applications, for example, biofuel production, degradation of wastewater, and filtration of drinking water (Flemming et al., 2016b). The negative impact of biofilm includes bio-fouling (Flemming, 2011), corrosion (Little and Lee, 2015), and deterioration of the drinking water quality (Wingender and Flemming, 2011). All higher eukaryotes, including humans, are populated by microorganisms that form biofilms (De Vos, 2015). Human dental plaque, skin, and gut represent one of the dominant biofilms in eukaryotic habitats. The widespread uses of medical devices create several new niches for bacterial biofilm formations (Qvortrup et al., 2019).

Cells in biofilm survive harsh growth conditions as biofilms are surrounded by high molecular weight extracellular polymeric substances (EPS) that attach cells (Branda et al., 2005; Flemming and Wingender, 2010). The EPS are composed of proteins, lipids, polysaccharides, and extracellular DNA and play an essential function in the pathogenesis of the numerous microbial infections (Ch'ng et al., 2019). It has also been reported that microbial cells inside the biofilms are found to be resistant against UV, metal toxicity, acid exposure, desiccation, $\mathrm{pH}$ gradients, etc. (Costerton et al., 1999; Hall-Stoodley et al., 2004). In accretion to various physical and chemical tolerances, EPS confers immune resistance to many resident pathogenic microbes within biofilms by inhibiting neutrophil-mediated phagocytosis (Gunn et al., 2016). Izano et al. (2009) reported that the eDNA and intercellular adhesins of EPS act as a barrier for the penetration of a variety of antimicrobials. The eDNA present within the EPS chelate human antimicrobial peptides (AMPs) and lessen the antimicrobial activity of these peptides (Jones et al., 2013). So far, many studies have been carried out to identify the method of biofilm formation and subsequent preventive strategies to strike the challenges, especially the drug resistance due to biofilm formation (Roy et al., 2018).

The presence of glycocalyx, outer membrane structure, and efflux pumps; and heterogeneity in growth rate, genetic adaptation, metabolic state, and metabolism of cells within a biofilm are the leading causes of biofilm that acquire resistance against antimicrobials (Singh et al., 2017). The mode of biofilm establishment in several human pathogens, as well as its drug resistance mechanism, is well documented and reviewed by different researchers and plotted (Figure 1). This figure explains the shared mechanism of biofilm tolerance under three sections. (1) Physical tolerance: the excess production of EPS restricts the penetration and diffusion of antimicrobials; as a result, cells in the biofilm get more time to become tolerant. Similar observations found that EPS production augments antimicrobial tolerance; an isogenic $\Delta c s g D$ mutant of Salmonella Typhimurium (EPSdeficient mutant) is much susceptible to hydrogen peroxide (MacKenzie et al., 2017) and ciprofloxacin (Tabak et al., 2009). Therefore, therapeutic strategies that destabilize and inhibit EPS are the best anti-biofilm approaches to inhibit biofilms and reduce significant problems of antimicrobial resistance. A similar observation has been recorded by Deokar and Kadam (2020) and Dieltjens et al. (2020) that EPS inhibition reduces cell adhesion as well as drug tolerance in biofilms. (2) Passive tolerance: enzymes present in the biofilm matrix inactivate the antimicrobial molecules. The mechanism for the neutralization of antimicrobials through the biofilm matrix components have also been reported (Fux et al., 2005), and there are reports that catalase enzymes present in the biofilm matrix are responsible for tolerance of Staphylococcus epidermidis biofilm against various physicochemical agents (Olwal et al., 2019). (3) Physiological tolerance: metabolically inactive cells in the deeper layers of biofilm exhibit adaptive stress responses that regulate the tolerance of biofilms to various antimicrobials. Persister cells become more tolerant of a variety of antibiotics after phenotypic and reversible changes induced by starvation, ecological factors, and several other adaptive responses such as SOS and stringent response (Harms et al., 2016; Ciofu and Tolker-Nielsen, 2019; Soares et al., 2019).

Persister cells are slow-dividing bacteria, less susceptible to antibiotics, and they have an essential role for biofilm reestablishment (Dawson et al., 2011). Persister cells upregulate the expression of various toxin-antitoxin genes that blocks translation which leads to lessen cellular metabolism and eventually guarantees their survival in the presence of antibiotics (Lewis, 2005). These cells revive to vegetative dividing cells to reoccur infection after the end of antibiotic action (Lewis, 2010). Persister cells have been confined from antibiotics because these cells express the toxin-antitoxin system where the antibiotic target is blocked by the toxin module (Lewis, 2005). Oxygen scarcity and little metabolic activity in biofilms provide $P$. aeruginosa greater tolerance to many antibiotics (Wilkins et al., 2014). Sudden changes in $\mathrm{pH}$ between layers in a biofilm play a role to accumulate organic acids, thus deactivating the penetrating compounds (Wilkins et al., 2014). The development of gradients of oxygen, $\mathrm{pH}$, nutrients, and electron acceptors all over the biofilm makes microenvironments where cells respond by altering their gene expression (Spormann, 2008; Stewart and Franklin, 2008). Complex (polymicrobial) biofilm made up of many species is generally more resistant to antibiotics than biofilm made up of a single species (Van der Veen and Abee, 2011). Cell diversity and 


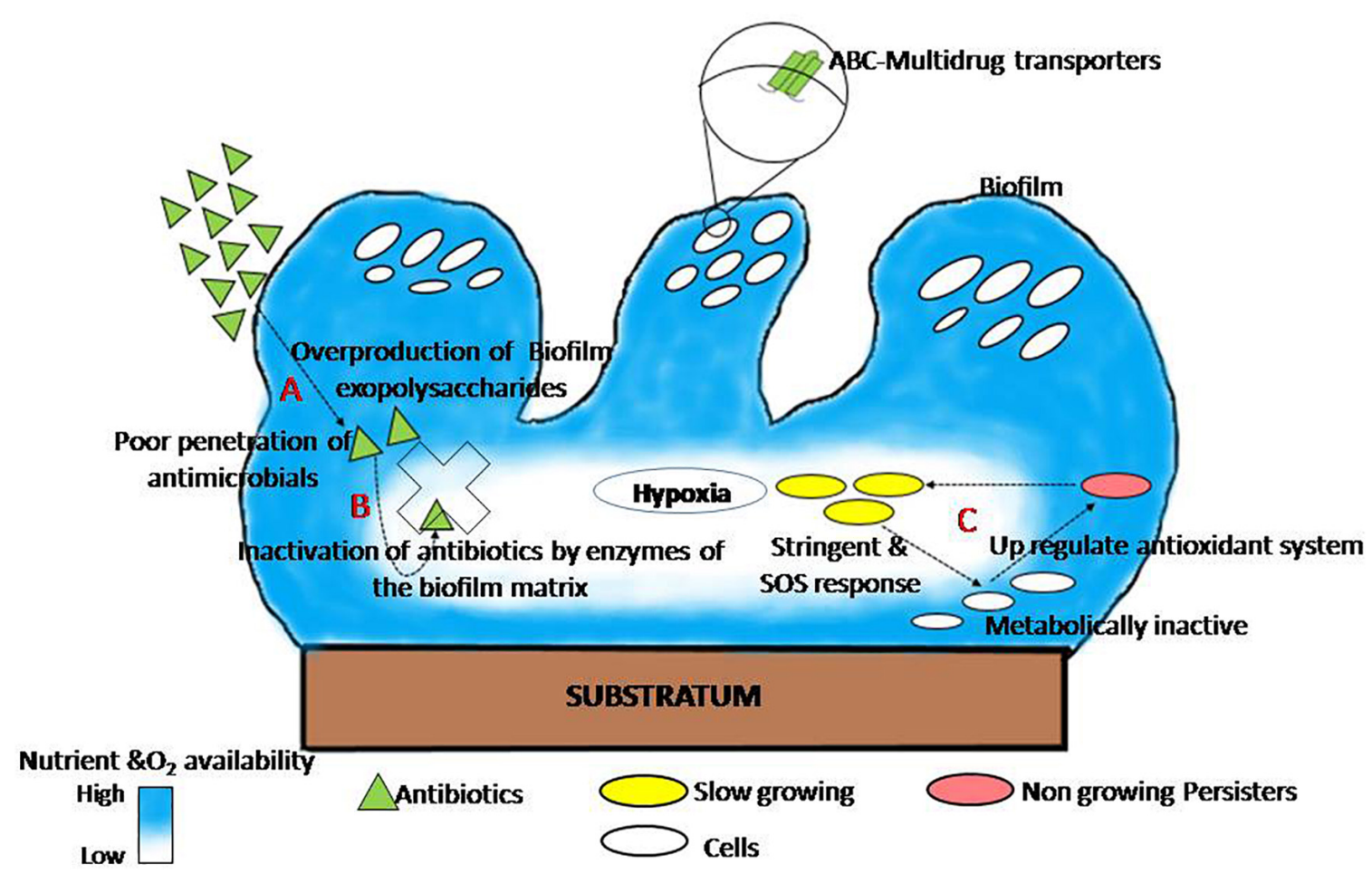

FIGURE 1 | The general mechanism of biofilm tolerance to various antimicrobials. (A) Physical tolerance: biofilm matrix limits the diffusion of antimicrobials (Tseng et al., 2013). (B) Passive tolerance: matrix enzymes inactivate the penetrated antibiotics molecules (Fux et al., 2005). (C) Physiological tolerance: persister cells in the deeper layer of biofilm induce adaptive SOS response and thus become more tolerant (adapted from Ciofu and Tolker-Nielsen, 2019).

metabolic conditions play the most important role in antibiotic tolerance of biofilms.

However, with the advance of sequencing technology, a ton of genomic data have been generated, which allows further illustration of the unknown molecular mechanism in the association of biofilm formation and drug resistance. The RNAseq transcriptome analysis identified arsenic resistance operon genes (arsR and $\operatorname{ars} D)$, sporulation regulatory gene (paiA), $\mathrm{ABC}$ drug transporter classes, and penicillin-binding proteins associated with the Enterococcus faecalis biofilm formation and drug resistance (Seneviratne et al., 2017). They found higherlevel expression of $a r s D$ in biofilm mode to avoid cell toxicity and suggested that $a r s D$ gene knockout could be a possible way of inhibiting biofilm formation. Similarly, they also observed the reduced level of expression of the paiA gene in biofilms. Padhi et al. (2016) reported that Mtb Rv0024 protein expression plays a significant role in the biofilm formation and subsequent resistance against anti-tuberculosis drugs in non-pathogenic Mycobacterium smegmatis strain.

The present tendency of antifungal tolerance is also a significant area of concern; therefore, direct research in a direction of novel antifungal compounds with targeted mechanisms of action are required (Sharma and Bisht, 2020). Many studies reported that the biofilm of Candida albicans is tolerant to many antifungal drugs as compared with the planktonic yeast cells. Moreover, the formation of mannanglucan complex promoted by the extracellular vesicles (EVs) is also linked to drug resistance and reported in C. albicans, C. glabrata, C. tropicalis, and C. parapsilosis (Mitchell et al., 2015; Dominguez et al., 2018; Zarnowski et al., 2018). It has also been reported that overexpression of efflux pumps, a mutation in the target site of the drug, persisted cells, the interaction between biofilm and host immunity system as well as proteins associated with the filamentation process were involved in the biofilm-associated resistance mechanism of fungi (Borghi et al., 2016). Analyzing the transcriptional network regulating biofilm growth of C. albicans illustrates six major transcription regulators such as Efg1 and Tec1 for cell morphology regulation; Bcr1, Brg1, and Ndt80 for biofilm formation; and Tec1 and Rob1 which controls the normal process of biofilm formation (Fox and Nobile, 2012; Uppuluri et al., 2018). Thus, an in-depth understanding of the molecular pathway involved in the biofilm formation and subsequent antibiotic resistance is essential to formulate the preventive measures. This review aims to focus on the natural anti-biofilm agents effective against a broad range of microbial biofilms and strategies related to recent biofilm treatments.

\section{Anti-biofilm Agents Based on Natural Products}

The formation and development of biofilms is a complicated procedure involving different stages which can be the target of natural anti-biofilm agents for the prevention of biofilm 
development. Some of the well-studied stages of biofilm development include (1) attachment of bacterial cells to a suitable biotic/abiotic surface, (2) development of biofilm structure, (3) maturation of biofilm, and (4) dispersion (Boles and Horswill, 2008). The first two stages are highly critical in the development of biofilms and targeting one or both of these stages seems to be the ideal strategy for inhibition of biofilm formation. The attachment stage involves cytoskeletal elements (predominantly flagella, fimbriae) and lipopolysaccharides as key players. Surface signaling/communication of a group of bacteria, also termed as Quorum Sensing is a key player in the formation of biofilm. The natural anti-biofilm agents either act solely or synergistically by diverse mechanisms, as illustrated in Figure 2.

\section{Phytochemicals}

There are broadly five classes of natural compounds that have high anti-biofilm properties. Those are phenolics, essential oils, terpenoids, lectins, alkaloids, polypeptides, and polyacetylenes (Yong et al., 2019). Phenolics are a group of compounds. It has seven subclasses which include phenolic acids, quinones, flavonoids, flavones, flavonols, tannins, and coumarins, out of which tannins, specifically condensed tannins, have anti-biofilm activity (Trentin et al., 2011). These entire compounds act on biofilm by six main mechanisms like substrate deprivation, membrane disruption, and binding to adhesin complex and cell wall; bind to proteins; interact with eukaryotic DNA; and block viral fusion (Cowan, 1999; Lu et al., 2019).

Several solvents, i.e., water, methanol, ethanol, chloroform, ether, dichloromethanol, and acetone, were used for the extraction of natural compounds from various sources for anti-biofilm activity. Various experiments carried out by researchers found that water extracts anthocyanins, sugars like tannins, saponins, terpenoids, polypeptides, and lectins. Ethanol extracts compounds, i.e., tannins, polyphenols, polyacetylenes, flavonol, terpenoids, sterols, alkaloids, and propolis whereas methanol extracts anthocyanins, terpenoids, saponins, tannins, xanthoxyllines, quassinoids, totarol, flavones, lactones, phenones, and polyphenols (Cowan, 1999). Extraction with chloroform yields terpenoids and flavonoids; dichloromethanol yields only terpenoids (Cowan, 1999); ethers when used as solvent results in the extraction of terpenoids, alkaloids, fatty acids, and coumarins whereas acetone isolates flavonols. Hydroquinone and caffeic acid methyl ester, isolated from Cnestis ferruginea Vahl ex DC. aqueous extract, showed promising results against S. aureus (Kouakou et al., 2019). Many researchers worked on bioactive compounds from medicinal plants for the discovery of novel natural anti-biofilm compounds. The anti-biofilm properties of Indian medicinal plants have been exploited and found that Cinnamomum glaucescens (Nees) Hand.-Mazz, Syzygium praecox Roxb. Rathakr. \& N. C. Nair, Bischofia javanica Blume, Elaeocarpus serratus L., Smilax zeylanica L., Acacia pennata (L.) Willd., Trema orientalis (L.) Blume, Acacia pennata (L.) Willd., Holigarna caustica (Dennst.) Oken, Murraya paniculata (L.) Jack, and Pterygota alata (Roxb.) R. Br. extracts have promising anti-biofilm activity against S. aureus (Panda et al., 2020). 12-Methoxy-trans-carnosic acid and carnosol identified from the methanolic extract of Salvia officinalis L., an Algerian medicinal plant, have shown antibiofilm activity against Candida biofilm in in vitro conditions (Kerkoub et al., 2018).

Phytochemicals inhibit the quorum sensing mechanism mainly by blocking the quorum sensing inducers like AHL, autoinducers, and autoinducers type 2 (Ciric et al., 2019). Garlic extracts play a vital role in the inhibition of quorum sensing signaling molecules of Pseudomonas and Vibrio spp. biofilms (Harjai et al., 2010; Lu et al., 2019). Emodin helps in the proteolysis of transcription factors associated with the quorum sensing and acts as its potent inhibitor (Ding et al., 2011). Quorum quenchers, along with antibiotics, are the best alternative anti-biofilm agents, as discussed by many researchers (Paluch et al., 2020). Phytochemicals also play a significant role in inhibiting bacterial adhesions and suppression of genes related to biofilm formation (Adnan et al., 2020). Biofilm development at the initial stages can be outlawed by interfering with the forces (Van der Waals force of attraction, electrostatic attraction, sedimentation and Brownian movements) which are responsible for the support of bacterial attachment to various surfaces (Roy et al., 2018). Phytocompounds have the potential to interfere with the extension along with the capability to stop the accessibility to nutrients essential for adhesion and bacterial growth (Sandasi et al., 2010).

There are reports on the anti-adhesive properties of ethanolic and acetone extract of Psidium guajava L. (Razak and Rahim, 2003) and extracts from various Eugenia spp. on C. albicans (Sardi et al., 2017). An alkaloid (norbgugaine) has shown a significant effect on $P$. aeruginosa biofilm by preventing adhesion due to loss of cell motility (Majik et al., 2013). A very recent study on Adiantum philippense L. crude extract has shown a promising role in decreasing the content of biofilm exopolysaccharides (Adnan et al., 2020). They observed that Adiantum philippense L. crude extract restrains biofilm at the initial stages by targeting adhesin proteins, deforming the pre-formed biofilms, and obstructing EPS production. Various researchers identified a different group of phytocompounds especially polyphenols such as 7-epiclusianone, tannic acid, and casbane which prevent cell surface attachment (Murata et al., 2010; Carneiro et al., 2011; Payne et al., 2013; Adnan et al., 2020).

Members of Enterobacteriaceae express curli, an amyloid fiber on the cell surface that helps in the attachment to characters and cell aggregation and enhances biofilm formation as well as cellular invasion (Tursi et al., 2020). Cegelski et al. (2009) found that pyridones affect the expression of the CsgA curli subunit and hamper curli biogenesis. Phloretin, ginkgolic acid, and phytocompounds from Malaysian plants help in the regulation of curli and pilli genes (Lee et al., 2011, 2014a,b; Johari et al., 2020). Vikram et al. (2013) reported that a citrus sterol $\beta$-sitosterol glucoside inhibited E. coli O157:H7 biofilm formation and motility by suppressing flagellar operon flhDC. The phytocompounds of curlicide and pilicide nature can be exploited in therapeutic strategies of Enterobacteriaceae biofilm prevention (Johari et al., 2020). Phytocompounds having fewer side effects can be a better therapeutic agent for biofilm-related 


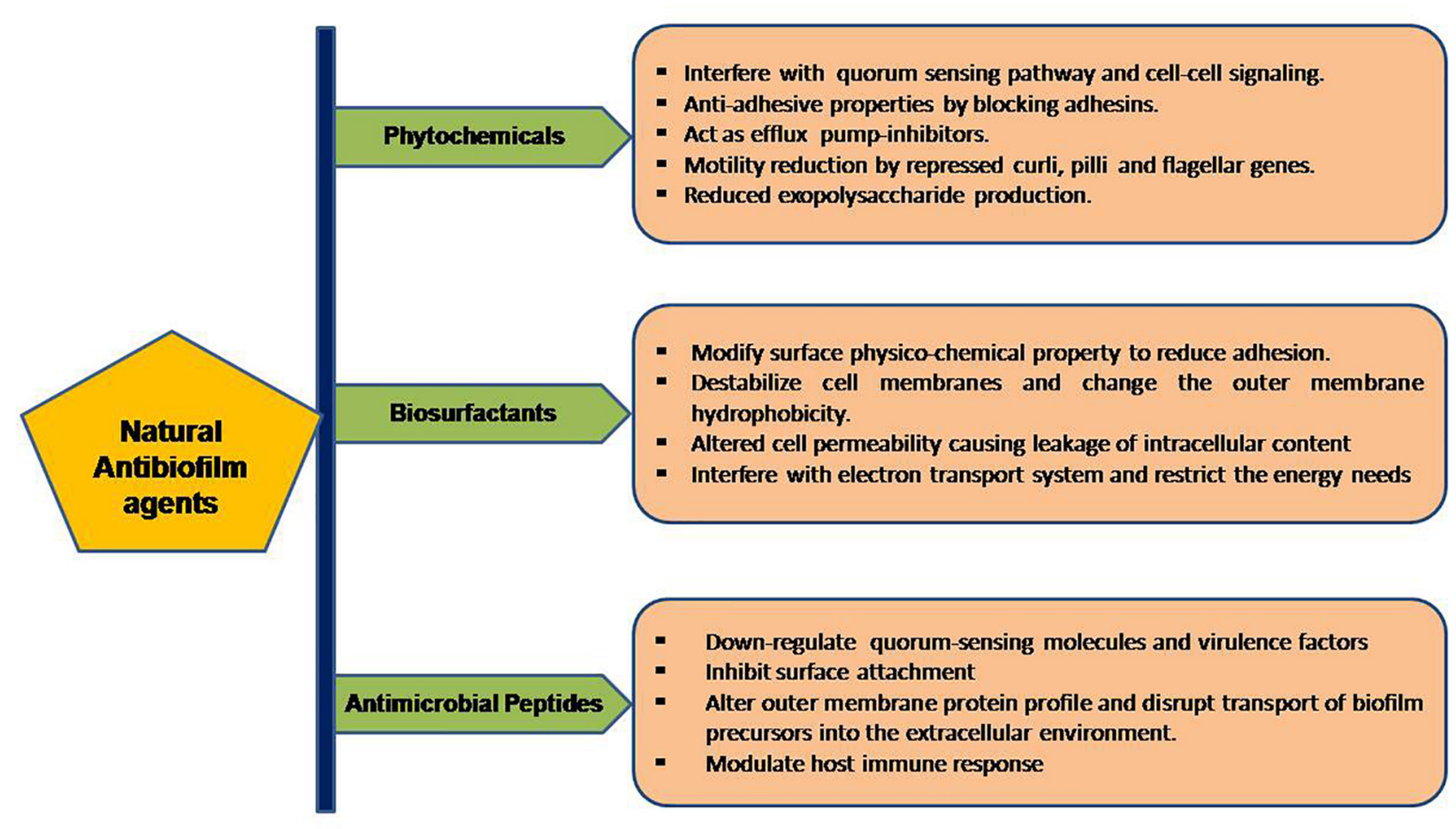

FIGURE 2 | Workflow of the portrayed natural anti-biofilm agents based on their mode of actions.

infections, but recent reports suggest a combined approach which is always better than the individualistic approach. Few plantbased antimicrobials with the potential of anti-biofilm activity are summarized in Table $\mathbf{1 .}$

\section{Biosurfactants}

Biosurfactants (BS) hinder biofilm formation by varying the cell adhesion ability through less cell surface hydrophobicity, membrane disruption, and inhibited electron transport chain, thus restricting cellular energy demand (Satpute et al., 2016). Biosurfactants of different classes are produced by various microorganisms that exhibit antibacterial, antifungal, and anti-biofilm activities (Paraszkiewicz et al., 2019). The effect of biosurfactants from Lactobacillus plantarum and Pediococcus acidilactici on quorum sensing signaling molecules and expressions of biofilm-linked genes in Staphylococcus aureus was evaluated (Yan et al., 2019). They reported that biosurfactants reduce the growth of $S$. aureus biofilm by regulating the expression of biofilm-related genes $d l t B$, icaA, cidA, etc. BS from Lactobacillus plantarum significantly reduced cidA gene expression at $12.5 \mathrm{mg} / \mathrm{ml}$ (Yan et al., 2019). Biosurfactant from Pediococcus acidilactici downregulates the gene expression of autoinducer-2 (AI-2) signaling molecules, accessory gene regulator (agr $A$ ), and staphylococcal accessory regulatory (sar A) at $50 \mathrm{mg} / \mathrm{ml}$ (Yan et al., 2019). Previous studies reported that the anti-biofilm activity of Lactobacillus-derived BS loaded liposomes had greater ability than free BS to inhibit S. aureus (MRSA) biofilm formation and elimination (Giordani et al., 2019). Few biosurfactants along with their consequence on biofilm growth, development, and dispersal are summarized in Table 2.

Ohadi et al. (2020) identified an anionic lipopeptide from Acinetobacter junii which self-aggregates to form $\beta$ sheet-rich biosurfactant vesicles. This biosurfactant is thermostable and less toxic, so it can be used as an anti-biofilm agent. Biofilms that are developed by dermatophytes are very difficult to eradicate. A lipopeptide biosurfactant obtained from Beauveria bassiana, which is an insect-attacking fungus, plays an important role as an anti-biofilm agent in ex vivo conditions for M. canis (Abdel-Aziz et al., 2020). It acts by disrupting cell membrane integrity and interfering with cell membrane permeability. The biosurfactant from B. bassiana overcome the disadvantage of expensive production as it was produced from steep corn liquor. This can be a promising biosurfactant for recalcitrant dermatophytosis. Surfactin, a cyclic lipopeptide, was found to be very effective along with its metal complex against $C$. albicans biofilm-related infections. This biosurfactant also controls the expression of hyphal specific genes and mainly act by decreasing cellular surface hydrophobicity (Janek et al., 2020).

Rhamnolipids produced from Pseudomonas aeruginosa MN1 have higher anti-adhesive and anti-biofilm activity than that of surfactin (Abdollahi et al., 2020). Glycolipid isolated from Burkholderia sp. WYAT7, an endophyte of Artemisia nilagirica (Clarke) Pamp, has anti-biofilm activity against $S$. aureus (Ashitha et al., 2020). A broad-range glycolipoprotein, rich in Leu-His-Trp amino acids identified from Acinetobacter indicus M6 has low toxicity and removed $82.5 \%$ of biofilm at a 
TABLE 1 | Anti-biofilm activity of phytocompounds with their mechanism of action.

\begin{tabular}{|c|c|c|c|c|c|c|}
\hline Compound & Source & Experimental details & Pathogenic species & Molecular mechanism & Inhibitory concentration & References \\
\hline Ajoene & $\begin{array}{l}\text { Allium sativum } \\
\text { L. }\end{array}$ & $\begin{array}{l}\text { In vitro (PMNs killing } \\
\text { assays) and in vivo } \\
\text { (pulmonary infection mice } \\
\text { model) }\end{array}$ & $\begin{array}{l}\text { Pseudomonas } \\
\text { aeruginosa } \\
\text { P. aeruginosa } \\
\text { Staphylococcus } \\
\text { aureus }\end{array}$ & $\begin{array}{l}\text { Downregulates rhamnolipid production } \\
\text { Inhibits small regulatory RNA molecules (rsmY, } \\
\text { rsmZ, and rnalll) that operate in the later phase of } \\
\text { QS signaling }\end{array}$ & $\begin{array}{l}20 \mu \mathrm{g} / \mathrm{ml} \text { ajoene reduces } \\
\text { rhamnolipid production by } 1 / 3 \\
\mathrm{IC}_{50} \text { for } \\
r \mathrm{smY}=2.5 \mu \mathrm{g} / \mathrm{ml} \\
r s m Z=2.3 \mu \mathrm{g} / \mathrm{ml}\end{array}$ & $\begin{array}{l}\text { Jakobsen et al., } \\
2012 \\
\text { Jakobsen et al., } \\
2017\end{array}$ \\
\hline Allicin & $\begin{array}{l}\text { Allium sativum } \\
\text { L. }\end{array}$ & $\begin{array}{l}\text { In vitro } \\
\text { ( } \triangle \text { pqs } A B C D \text { knockout } \\
\text { strain) }\end{array}$ & $\begin{array}{l}\text { Pseudomonas } \\
\text { aeruginosa }\end{array}$ & $\begin{array}{l}\text { Decreases the bacterial adhesion in the initial } \\
\text { stages of biofilm formation as it reduces EPS } \\
\text { formation } \\
\text { It controls the expression of virulence factors hence } \\
\text { interfere with the QS system }\end{array}$ & $\begin{array}{l}250 \mu \mathrm{M} \text { inhibit production of } \\
\text { virulence factors such as } \\
\text { pyocyanin, elastase, and } \\
\text { pyoverdine and rhamnolipids }\end{array}$ & Xu et al., 2019 \\
\hline $\begin{array}{l}\text { Carvacrol } \\
\text { (monoterpenoid) }\end{array}$ & $\begin{array}{l}\text { Origanum } \\
\text { vulgare L. }\end{array}$ & $\begin{array}{l}\text { In vitro } \\
\text { (qPCR for relative } \\
\text { expression of las//lasR } \\
\text { genes) and docking } \\
\text { modeling of proteins Lasl } \\
\text { and LasR }\end{array}$ & $\begin{array}{l}\text { Pseudomonas } \\
\text { aeruginosa }\end{array}$ & $\begin{array}{l}\text { Post-translational inhibition against lasl, which } \\
\text { effects AHL production. It mainly acts on QS } \\
\text { machinery }\end{array}$ & $\begin{array}{l}\text { C6-AHL production reduced up } \\
\text { to } 80 \% \text { with } 1.9 \mathrm{mM} \text { of } \\
\text { carvacrol }\end{array}$ & $\begin{array}{l}\text { Tapia- } \\
\text { Rodriguez } \\
\text { et al., } 2019\end{array}$ \\
\hline $\begin{array}{l}\text { Emodin } \\
\text { (anthraquinone) }\end{array}$ & $\begin{array}{l}\text { Polygonum } \\
\text { cuspidatum } \\
\text { Siebold \& Zucc. } \\
\text { and } \\
\text { Rheum } \\
\text { palmatum L. }\end{array}$ & $\begin{array}{l}\text { In vitro } \\
\text { (crystal violet biofilm assay } \\
\text { and SEM analysis) }\end{array}$ & Staphylococcus aureus & $\begin{array}{l}\text { Decreases the release of eDNA and downregulates } \\
\text { the expression of biofilm-forming related genes like } \\
\operatorname{cid} A \text {, icaA, dlttB, agrA, sortaseA, and sarA }\end{array}$ & $\mathrm{MIC}=8 \mu \mathrm{g} / \mathrm{ml}$ & Yan et al., 2017 \\
\hline $\begin{array}{l}\text { Emodin } \\
\text { (anthroquinone) }\end{array}$ & $\begin{array}{l}\text { Rheum } \\
\text { palmatum L. }\end{array}$ & $\begin{array}{l}\text { In vitro (microdilution assay, } \\
\text { kinase assay) and } \\
\text { molecular docking for } \\
\text { emodin in CK2 (Autodock } \\
\text { Vina) }\end{array}$ & $\begin{array}{l}\text { Candida albicans } \\
\text { Candida krusei } \\
\text { Candida } \\
\text { parapsilosis } \\
\text { Candida tropicalis }\end{array}$ & $\begin{array}{l}\text { Biofilm formation is inhibited by targeting cellular } \\
\text { kinase signaling } \\
\text { It acts on planktonic cells by reducing hyphal } \\
\text { formation. It acts as a competitive inhibitor of CK2 }\end{array}$ & $\begin{array}{l}\mathrm{MIC}=12.5 \mu \mathrm{g} / \mathrm{ml} \\
\mathrm{MFC}=25 \mu \mathrm{g} / \mathrm{ml} \\
\mathrm{MIC} \text { and MFC }=25 \mu \mathrm{g} / \mathrm{ml} \\
\mathrm{MIC} \text { and MFC }=50 \mu \mathrm{g} / \mathrm{ml}\end{array}$ & $\begin{array}{l}\text { Janeczko et al., } \\
2017\end{array}$ \\
\hline Aloe-emodin & $\begin{array}{l}\text { Rheum } \\
\text { officinale Baill. }\end{array}$ & $\begin{array}{l}\text { In vitro } \\
\text { (CLSM assays and Congo } \\
\text { red assay) }\end{array}$ & Staphylococcus aureus & $\begin{array}{l}\text { Reduce the production of extracellular proteins and } \\
\text { polysaccharide intercellular adhesin }\end{array}$ & $\begin{array}{l}\text { Inhibited biofilm formation on } \\
\text { polyvinyl chloride surfaces at } \\
32 \mu \mathrm{g} / \mathrm{ml}\end{array}$ & $\begin{array}{l}\text { Xiang et al., } \\
2017\end{array}$ \\
\hline Hordenine & $\begin{array}{l}\text { Hordeum } \\
\text { vulgare L. } \\
\text { (sprouting) }\end{array}$ & $\begin{array}{l}\text { In vitro } \\
\text { (SEM and CLSM assays, } \\
\text { qPCR for QS-related } \\
\text { genes) }\end{array}$ & $\begin{array}{l}\text { Pseudomonas } \\
\text { aeruginosa }\end{array}$ & $\begin{array}{l}\text { Decreases AHL production } \\
\text { Virulence factors (proteases, elastase, pyocyanin, } \\
\text { rhamnolipid, alginate, and pyroviridine) production } \\
\text { decreased significantly. Inhibit swimming and } \\
\text { swarming activity } \\
\text { Down-regulates the expression of lasl, lasR, rhll and } \\
\text { rhlR genes. }\end{array}$ & $\begin{array}{l}1 \mathrm{mg} / \mathrm{ml} \text { of hordenine along } \\
\text { with } 0.4 \mu \mathrm{g} / \mathrm{ml} \text { of netilmicin } \\
\text { reduced } \\
\text { biofilms by } 88 \% \\
\text { C4-HSL production decreased } \\
\text { up to } 69 \% \text { at } 0.5 \mathrm{mg} / \mathrm{ml}\end{array}$ & $\begin{array}{l}\text { Zhou et al., } \\
2018\end{array}$ \\
\hline $\begin{array}{l}\text { Pulverulentone } \\
\text { A }\end{array}$ & $\begin{array}{l}\text { Callistemon } \\
\text { citrinus (Curtis) } \\
\text { skeels leaves }\end{array}$ & $\begin{array}{l}\text { In vitro } \\
\text { (broth microdilution assay, } \\
\text { CLSM, TEM analysis) }\end{array}$ & $\begin{array}{l}\text { Methicillin-resistant } \\
\text { Staphylococcus aureus }\end{array}$ & $\begin{array}{l}\text { Reduces styphyloxanthin production, thus inhibiting } \\
\text { biofilm formation } \\
\text { Disrupts the cell membrane }\end{array}$ & $\begin{array}{l}\mathrm{MIC}=125 \mu \mathrm{g} / \mathrm{ml} \\
\text { Production of the virulence } \\
\text { factor decreased by } 65.9 \%\end{array}$ & $\begin{array}{l}\text { Shehabeldine } \\
\text { et al., } 2020\end{array}$ \\
\hline
\end{tabular}


TABLE 1 | Continued

\begin{tabular}{|c|c|c|c|c|c|c|}
\hline Compound & Source & Experimental details & Pathogenic species & Molecular mechanism & Inhibitory concentration & References \\
\hline Vitexin (flavon) & Vitex species & $\begin{array}{l}\text { In vitro (safranin staining, } \\
\text { microscopy methods, EPS } \\
\text { quantification) } \\
\text { In vivo murine model } \\
\text { (catheter-associated infection), } \\
\text { molecular docking }\end{array}$ & Pseudomonas aeruginosa & $\begin{array}{l}\text { Attenuates formation of } \\
\text { EPS, QS-associated } \\
\text { factors (swarming motility, } \\
\text { production of protease, } \\
\text { pyoverdin and pyocyanin) } \\
\text { Molecular docking studies } \\
\text { confirmed it attnuates Las } \\
\text { A, Las B, and Lux R }\end{array}$ & $\begin{array}{l}\mathrm{MIC}=260 \mu \mathrm{g} / \mathrm{ml} \\
39.04 \% \text { decrease in Las A } \\
\text { protease and } 37.54 \% \text { Las } \\
\text { B elastase }\end{array}$ & Das et al., 2016 \\
\hline 5-Hydroxymethylfurfural & $\begin{array}{l}\text { Musa } \\
\text { acuminata } \\
\text { Colla. }\end{array}$ & $\begin{array}{l}\text { In vitro } \\
\text { (biofilm, Las B elastase, } \\
\text { protease, and rhamnolipid } \\
\text { quantification assays) }\end{array}$ & Pseudomonas aeruginosa & $\begin{array}{l}\text { Inhibits the production of } \\
\text { biofilm proteins, EPS, and } \\
\text { cell surface hydrophobicity } \\
\text { productions } \\
\text { Downregulates the } \\
\text { expression of QS-regulated } \\
\text { virulence genes }\end{array}$ & $\begin{array}{l}\text { MBIC }=400 \mu \mathrm{g} / \mathrm{ml} \\
\text { Reduces production of } \\
\text { biofilm proteins, biofilm } \\
\text { adherence, EPS and CSH } \\
\text { to the level of } 79,82 \text {, and } \\
77 \% \text {, respectively } \\
\text { Inhibits the production of } \\
\text { LasA protease, LasB } \\
\text { elastase, pyocyanin, } \\
\text { alginate, and rhamnolipid } \\
77,75,68,80,78 \text {, and } \\
69 \% \text {, respectively }\end{array}$ & $\begin{array}{l}\text { Vijayakumar and } \\
\text { Ramanathan, } 2020\end{array}$ \\
\hline Phytol & Piper betle L. & $\begin{array}{l}\text { In vitro } \\
\text { (microscopic analysis, } \\
\text { transcriptional analysis of } \\
\text { QS-regulated genes) }\end{array}$ & Serratia marcescens & $\begin{array}{l}\text { Inhibits the swarming } \\
\text { motility and hydrophobicity } \\
\text { Downregulates QS genes }\end{array}$ & $\begin{array}{l}\text { Significantly inhibits the } \\
\text { production of biofilm and } \\
\text { EPS to the level of } 65 \text { and } \\
43 \%\end{array}$ & Srinivasan et al., 2016 \\
\hline \multirow[t]{2}{*}{$\begin{array}{l}\text { Isolimonic acid and } \\
\text { ichangin }\end{array}$} & Citrus species & $\begin{array}{l}\text { In vitro } \\
\text { (Caco-2 cell adhesion and } \\
\text { survival assay, Al-3 reporter } \\
\text { assay) }\end{array}$ & $\begin{array}{l}\text { Enterohaemorrhagic } \\
\text { Escherichia coli }\end{array}$ & $\begin{array}{l}\text { Decreases the adherence } \\
\text { Downregulates flagellar } \\
\text { genes, ler (transcriptional } \\
\text { regulator of LEE) } \\
\text { Represses the expression } \\
\text { of the flagellar master }\end{array}$ & $\begin{array}{l}\mathrm{IC}_{25} \text { (isolimonic } \\
\text { acid) }=19.7 \mu \mathrm{M} \\
\mathrm{IC}_{25} \text { (ichangin) }=28.3 \mu \mathrm{M} \\
\text { ler repressed by } 5 \text {-fold, fihC } \\
\text { and flhD repressed by } 4.6 \\
\text { and } 6.9 \text {, respectively }\end{array}$ & Vikram et al., 2012 \\
\hline & & & Vibrio harveyi & $\begin{array}{l}\text { regulator (flhC and flhD) } \\
\text { Regulates /uxO expression, } \\
\text { thus acting as potent } \\
\text { modulators of bacterial } \\
\text { cell-cell signaling }\end{array}$ & & Vikram et al., 2011 \\
\hline (R)-Bgugaine & $\begin{array}{l}\text { Arisarum } \\
\text { vulgare } \\
\text { O. Targ. Tozz. }\end{array}$ & $\begin{array}{l}\text { In vitro } \\
\text { (static biofilm } \\
\text { inhibition assay) }\end{array}$ & $\begin{array}{l}\text { Pseudomonas } \\
\text { aeruginosa }\end{array}$ & $\begin{array}{l}\text { Affects flagella related } \\
\text { functions, inhibits } \\
\text { pyocyanin pigmentation, } \\
\text { LasA protease, rhamnolipid } \\
\text { production. }\end{array}$ & $\begin{array}{l}\text { Reduces biofilm density by } \\
83 \% \text { at } 1.8 \mathrm{mM}\end{array}$ & Majik et al., 2013 \\
\hline
\end{tabular}




\begin{tabular}{|c|c|c|c|c|c|c|}
\hline Compound & Source & Experimental details & Pathogenic species & Molecular mechanism & Inhibitory concentration & References \\
\hline Zingerone & Zingiber officinale Roscoe & $\begin{array}{l}\text { In vitro } \\
\text { (microtiter plate assay, } \\
\text { motility assay, quorum } \\
\text { sensing signal molecules } \\
\text { quantitative assay) and } \\
\text { molecular docking of TraR, } \\
\text { LasR, and PqSR proteins }\end{array}$ & $\begin{array}{l}\text { Pseudomonas aeruginosa } \\
\text { PAO1 }\end{array}$ & $\begin{array}{l}\text { Reduces swimming, } \\
\text { swarming, and twitching } \\
\text { motility. Suppresses } \\
\text { pyocyanin, hemolysin, } \\
\text { rhamnolipid, protease and } \\
\text { elastase } \\
\text { Molecular docking analysis } \\
\text { proved that it could bind } \\
\text { with all the quorum sensing } \\
\text { receptors and stops } \\
\text { receptor-ligand interaction, } \\
\text { suppresses QS-dependent } \\
\text { gene expression }\end{array}$ & $\begin{array}{l}\text { Sub } \mathrm{MIC}=10 \mathrm{mg} / \mathrm{ml} \\
\text { Reduces the } \mathrm{BFC} \text { of } \\
P . \text { aeruginosa } \mathrm{PAO} 1 \text { as } \\
\mathrm{A}_{570} \text { from } 1.1 \text { to } 0.5\end{array}$ & Kumar et al., 2015 \\
\hline Baicalin & $\begin{array}{l}\text { Scutellaria baicalensis } \\
\text { Georgi }\end{array}$ & $\begin{array}{l}\text { In vivo } \\
\text { (mouse peritoneal implant } \\
\text { infection model) }\end{array}$ & Pseudomonas aeruginosa & $\begin{array}{l}\text { Inhibits LasA protease, } \\
\text { LasB elastase, pyocyanin, } \\
\text { rhamnolipid, motilities and } \\
\text { exotoxin A virulence factors } \\
\text { Decreases the expression } \\
\text { of lasl, lasR, rhll, rhlR, } \\
\text { pqsR, and pqSA genes and } \\
\text { reduces the QS signaling } \\
\text { molecule 3-oxo-C12-HSL } \\
\text { and C4-HSL }\end{array}$ & $\begin{array}{l}\text { MIC }>1024 \mu \mathrm{g} / \mathrm{ml} \\
\text { C4-HSL levels decreased } \\
77.2 \% \text { at } 64 \mu \mathrm{g} / \mathrm{ml} \text { baicalin }\end{array}$ & Luo et al., 2017 \\
\hline Curcumin & Curcuma longa L. & $\begin{array}{l}\text { In vitro } \\
\text { (crystal violet biofilm assay, } \\
\text { pellicle formation assay, } \\
\text { surface motility assay, } \\
\text { mixed culture biofilm assay) } \\
\text { In vivo (Caenorhabditis } \\
\text { elegans model organism, } \\
\text { C. elegans } \\
\text { killing assay) }\end{array}$ & $\begin{array}{l}\text { Acinetobacter baumannii, } \\
\text { C. albicans }\end{array}$ & $\begin{array}{l}\text { Inhibits pellicle formation, } \\
\text { Pilli motility, and ring biofilm } \\
\text { formation } \\
\text { Molecular docking analysis } \\
\text { proved that curcumin } \\
\text { interacts with the biofilm } \\
\text { response regulator BfmR }\end{array}$ & $\begin{array}{l}\text { MIC }>500 \mu \mathrm{g} / \mathrm{ml} \text { for } \\
\text { A. baumannii ATCC } 17978 \\
\text { planktonic cell } \\
\text { Reduces } A \text {. baumannii } \\
\text { ATCC } 17978 \text { biofilm } \\
\text { production by } 93 \% \text { at } \\
100 \mu \mathrm{g} / \mathrm{ml}\end{array}$ & Raorane et al., 2019 \\
\hline $\begin{array}{l}\text { Epigallocatechin-3-gallate } \\
\text { (EGCG) }\end{array}$ & $\begin{array}{l}\text { Camellia sinesis (L.) Kuntze } \\
\text { (green tea) }\end{array}$ & $\begin{array}{l}\text { In vitro } \\
\text { (growth assay, CR-binding } \\
\text { assay, TEM analysis) }\end{array}$ & Escherichia coli BW25113 & $\begin{array}{l}\text { Suppresses curli } \\
\text { production and expression } \\
\text { of curli-related proteins } \\
\operatorname{csg} A, \operatorname{csg} B \text {, and } \operatorname{csg} D \\
\text { Enhances the degradation } \\
\text { of sigma factor (RpoS) by } \\
\text { ClpXP protease }\end{array}$ & $\mathrm{IC}_{50}=5.9 \pm 0.8 \mu \mathrm{M}$ & Arita-Morioka et al., 2018 \\
\hline $\begin{array}{l}\text { Ginkgolic acid (GA) and } \\
\text { hydroginkgolic acid }\end{array}$ & Pistacia lentiscus L. (fruit) & $\begin{array}{l}\text { In vitro, in vivo (human lung } \\
\text { A549 infection model, } \\
\text { C. elegans infection model) }\end{array}$ & $\begin{array}{l}\text { Pseudomonas aeruginosa } \\
\mathrm{H} 103\end{array}$ & $\begin{array}{l}\text { Decreases virulence factor } \\
\text { production } \\
\text { Modifies the membrane } \\
\text { fluidity } \\
\text { Regulates virulence through } \\
\text { the ECFoSigX }\end{array}$ & $\begin{array}{l}\mathrm{IC}_{50} \text { of pyocyanin } \\
\text { inhibition }=6.3 \mu \mathrm{g} / \mathrm{ml} \\
100 \mu \mathrm{g} / \mathrm{ml} \mathrm{GA} \text { reduces } \\
\text { pyocyanin production by } \\
82 \%\end{array}$ & Tahrioui et al., 2020 \\
\hline
\end{tabular}


TABLE 1 | Continued

\begin{tabular}{|c|c|c|c|c|c|c|}
\hline Compound & Source & Experimental details & Pathogenic species & Molecular mechanism & Inhibitory concentration & References \\
\hline 7-Epiclusianone & $\begin{array}{l}\text { Rheedia brasiliensis } \\
\text { (Mart.) Planch. \& Triana }\end{array}$ & $\begin{array}{l}\text { In vivo } \\
\text { A rodent model of dental } \\
\text { caries }\end{array}$ & Streptococcus mutans & $\begin{array}{l}\text { Increases cariostatic activity } \\
\text { by disrupting insoluble } \\
\text { exopolysaccharides and } \\
\text { intracellular } \\
\text { polysaccharides }\end{array}$ & $\begin{array}{l}70-80 \% \text { less severe } \\
\text { smooth-surface lesions and } \\
50-70 \% \text { less severe } \\
\text { sulcal-surface lesions than } \\
\text { the vehicle control } \\
\text { treatment } \\
50-70 \% \text { reduction of } \\
\text { exopolysaccharides }\end{array}$ & $\begin{array}{l}\text { Murata et al., } 2010 \\
\text { Branco-de-Almeida et al., } \\
2011\end{array}$ \\
\hline Tannic acid & Not specified & $\begin{array}{l}\text { In vitro } \\
\text { (crystal violet microplate } \\
\text { biofilm assay, Congo red } \\
\text { binding assay) }\end{array}$ & E. coli BW25113 & $\begin{array}{l}\text { Efficiently killed bacteria in } \\
\text { pgaA mutant biofilms by } \\
\text { inhibiting the formation of } \\
\text { polysaccharide in the matrix } \\
\text { Affects intracellular SOS } \\
\text { response and decreases } \\
\text { the expression of genes } \\
\text { involved in this pathway }\end{array}$ & $\mathrm{MIC}=1 \mathrm{mg} / \mathrm{ml}$ & $\begin{array}{l}\text { Samoilova et al., 2019a } \\
\text { Samoilova et al., 2019b }\end{array}$ \\
\hline $\begin{array}{l}\text { Diterpene derivative } \\
\left(\mathrm{C}_{31} \mathrm{H}_{50} \mathrm{O}_{3}\right)\end{array}$ & $\begin{array}{l}\text { Myrmecodia pendens Merr. } \\
\text { \& L.M. Perry }\end{array}$ & $\begin{array}{l}\text { In vitro } \\
\text { (broth microdilution assay, } \\
\text { MBIC analysis by Perumal } \\
\text { method) }\end{array}$ & $\begin{array}{l}\text { Streptococcus mutans } \\
\text { ATCC } 25175\end{array}$ & Not specified & $\begin{array}{l}\mathrm{MBIC}=50 \mathrm{ppm} \text { and } \\
\mathrm{MIC}=40 \mathrm{ppm}\end{array}$ & Gartika et al., 2018 \\
\hline Chelerythrine & Bocconia cordata Willd. & $\begin{array}{l}\text { In vitro } \\
\text { (broth microdilution assay, } \\
\text { crystal violet assay) } \\
\text { and } \\
\text { in vivo (mono- and dual } \\
\text { species culture models) }\end{array}$ & $\begin{array}{l}\text { Candida albicans and } \\
\text { Staphylococcus aureus }\end{array}$ & $\begin{array}{l}\text { Inhibits hyphae formation } \\
\text { Reduces biofilm formation } \\
\text { by decreasing eDNA, } \\
\text { polysaccharide, and protein } \\
\text { levels }\end{array}$ & $\begin{array}{l}\text { The MICs } \\
\text { (monospecies) = } 4 \mu \mathrm{g} / \mathrm{ml} \\
\text { and MBICgos } \\
\text { (monospecies) }=2 \mu \mathrm{g} / \mathrm{ml} \\
\text { MICs (dual } \\
\text { species) }=6 \mu \mathrm{g} / \mathrm{ml} \text { and } \\
\text { MBIC } 90 \text { (dual } \\
\text { species) }=3 \mu \mathrm{g} / \mathrm{ml}\end{array}$ & Qian et al., 2020 \\
\hline Hyperforin & Hypericum perforatum $\mathrm{L}$. & $\begin{array}{l}\text { In vitro } \\
\text { (quorum sensing inhibition } \\
\text { assay, human plasma } \\
\text { protein-coated assay, static } \\
\text { microtiter plate crystal violet } \\
\text { assay) }\end{array}$ & $\begin{array}{l}\text { Staphylococcus aureus } \\
\text { AH1872 }\end{array}$ & $\begin{array}{l}\text { Exhibits anti-biofilm activity } \\
\text { and a moderate amount of } \\
\text { quroum quenching activity, } \\
\text { but a detailed mechanism } \\
\text { is not specified }\end{array}$ & $\begin{array}{l}\mathrm{MIC}_{50} \text { (flowering aerial } \\
\text { part) }=0.512 \% \mathrm{~V} / \mathrm{V} \\
\text { Exhibit moderate inhibition } \\
\text { of quorum sensing } \\
\left(\mathrm{QSIC}_{50}=0.064-0.512 \%\right. \\
\mathrm{V} / \mathrm{V})\end{array}$ & Lyles et al., 2017 \\
\hline $\begin{array}{l}\text { Warburganal, polygodial, } \\
\text { alpha-linolenic acid (ALA) }\end{array}$ & $\begin{array}{l}\text { Warburgia ugandensis } \\
\text { Sprague subsp. } \\
\text { ugandensis }\end{array}$ & $\begin{array}{l}\text { In vitro } \\
\text { (tetrazolium reduction } \\
\text { assay, checkerboard assay) }\end{array}$ & $\begin{array}{l}\text { Candida albicans } \\
\text { Candida glabrata } \\
\text { S. epidermidis } \\
\text { S. aureus }\end{array}$ & $\begin{array}{l}\alpha, \beta \text {-unsaturated } \\
1,4 \text {-dialdehyde in } \\
\text { polygodial and warburganal } \\
\text { is responsible for the potent } \\
\text { antifungal activity on } \\
\text { developing biofilms } \\
\text { Polygodial affects } \\
\text { mitochondrial ATPase and } \\
\text { leads to reduced ergosterol } \\
\text { levels }\end{array}$ & $\begin{array}{l}\mathrm{BIC}_{50} \\
\text { (warburganal) }=4.5 \pm 1 \mu \mathrm{g} / \mathrm{ml} \\
\text { and } \mathrm{BIC}_{50}(\text { polygodial) } \\
10.8 \pm 5 \mu \mathrm{g} / \mathrm{ml} \\
\mathrm{BIC}_{50} \\
\text { (warburganal) }=37.9 \pm 8 \mu \mathrm{g} / \mathrm{ml} \\
\mathrm{BIC}_{50}(\text { ALA) }=25 \mu \mathrm{g} / \mathrm{ml}\end{array}$ & Kipanga et al., 2020 \\
\hline
\end{tabular}

NS, not specified. 
TABLE 2 | Biosurfactants reported recently with anti-biofilm activities.

\begin{tabular}{|c|c|c|c|c|c|}
\hline Class & Source microorganism & Pathogen strains & Effect on biofilm & Dose & References \\
\hline $\begin{array}{l}\text { Lipopeptide biosurfactants } \\
\text { (LPBs) }\end{array}$ & Acinetobacter junii & $\begin{array}{l}\text { Biofilm of Staphylococcus } \\
\text { aureus, Proteus mirabilis, } \\
\text { and Pseudomonas } \\
\text { aeruginosa }\end{array}$ & $\begin{array}{l}\text { Biofilm disruption } 35,10 \text {, } \\
\text { and } 32 \% \text {, respectively } \\
\text { Biofilm disruption } 52,31 \text {, } \\
\text { and } 70 \% \text {, respectively }\end{array}$ & $\begin{array}{l}1250 \mu \mathrm{g} / \mathrm{ml} \\
2500 \mu \mathrm{g} / \mathrm{ml}\end{array}$ & Ohadi et al., 2020 \\
\hline Lipopeptide & Beauveria bassiana & Microsporum canis & $25.76 \%$ biofilm eradication & $1.95 \mu \mathrm{g} / \mathrm{ml}$ & Abdel-Aziz et al., 2020 \\
\hline Lipopeptide surfactin-C15 & B. subtilis \#309 & Candida albicans & $\begin{array}{l}85 \% \text { inhibition to biofilm } \\
\text { formation }\end{array}$ & $960 \mu \mathrm{g} / \mathrm{ml}$ & Janek et al., 2020 \\
\hline Lipopeptide surfactin & Bacillus safensis F4 & $\begin{array}{l}\text { Staphylococcus } \\
\text { epidermidis }\end{array}$ & $80 \%$ anti-adhesive activity & $6.25 \mathrm{mg} / \mathrm{ml}$ & Abdelli et al., 2019 \\
\hline Lipopeptide pontifactin & $\begin{array}{l}\text { Pontibacter korlensis strain } \\
\text { SBK-47 }\end{array}$ & $\begin{array}{l}\text { Bacillus subtilis, } \\
\text { Staphylococcus aureus, } \\
\text { Salmonella typhi, and Vibrio } \\
\text { cholerae }\end{array}$ & 99\% anti-adhesive activity & $2 \mathrm{mg} / \mathrm{ml}$ & Balan et al., 2016 \\
\hline Lipopeptide & Bacillus subtilis AC7 & Candida albicans & $\begin{array}{l}\text { Reduced adhesion up to } \\
67-69 \% \text { and biofilm } \\
\text { formation up to } 56-57 \%\end{array}$ & $2 \mathrm{mg} / \mathrm{ml}$ & Ceresa et al., 2016 \\
\hline Glycolipoprotein & Acinetobacter indicus M6 & $\begin{array}{l}\text { Methicillin-resistant } \\
\text { Staphylococcus aureus }\end{array}$ & $82.5 \%$ removal of biofilm & $500 \mu \mathrm{g} / \mathrm{ml}$ & Karlapudi et al., 2020 \\
\hline Glycolipid & Burkholderia sp. WYAT7 & Staphylococcus aureus & $\begin{array}{l}41 \% \text { inhibition to biofilm } \\
\text { formation } \\
79 \% \text { inhibition to biofilm } \\
\text { formation }\end{array}$ & $\begin{array}{l}1 \mathrm{mg} / \mathrm{ml} \\
2 \mathrm{mg} / \mathrm{ml}\end{array}$ & Ashitha et al., 2020 \\
\hline Rhamnolipids & $\begin{array}{l}\text { Pseudomonas aeruginosa } \\
\text { MN1 }\end{array}$ & Streptococcus mutans & $\begin{array}{l}\text { Dissociation of } 67 \% \text { of the } \\
\text { preformed biofilm }\end{array}$ & $12.5 \mathrm{mg} / \mathrm{ml}$ & Abdollahi et al., 2020 \\
\hline Rhamnolipids & $\begin{array}{l}\text { Burkholderia thailandensis } \\
\text { E264 }\end{array}$ & $\begin{array}{l}\text { Streptococcus oralis, } \\
\text { Actinomyces naeslundii, } \\
\text { Neisseria mucosa, and } \\
\text { Streptococcus sanguinis }\end{array}$ & $\begin{array}{l}90 \% \text { inhibition of } \\
\text { S. sanguinis biofilm } \\
70 \% \text { inhibition of S. oralis } \\
\text { biofilm } \\
70 \% \text { inhibition of } \\
\text { N. mucosa biofilm } \\
50 \% \text { inhibition of } \\
\text { A. naeslundii biofilm }\end{array}$ & $\begin{array}{l}0.39 \mathrm{mg} / \mathrm{ml} \\
0.78 \mathrm{mg} / \mathrm{ml} \\
6.25 \mathrm{mg} / \mathrm{ml} \\
12.5 \mathrm{mg} / \mathrm{ml}\end{array}$ & Elshikh et al., 2017 \\
\hline Exopolysaccharides & Pandorea pnomenusa MS5 & Burkholderia cepacia & $\begin{array}{l}\text { Inhibit Burkholderia cepacia } \\
\text { biofilm formation }\end{array}$ & $0.25 \mathrm{mg} / \mathrm{ml}$ & Sacco et al., 2019 \\
\hline
\end{tabular}


concentration of $500 \mu \mathrm{g} / \mathrm{ml}$ (Karlapudi et al., 2020). The EPS from Pandoraea pnomenusa MS5 serves as an anti-biofilm agent against Burkholderia cepacia (Sacco et al., 2019). This surfactant is a heteropolysaccharide, with two functional carbonyls and hydroxyl groups, and has oil-emulsifying capacity.

Biosurfactants are appropriate coating agents for medical implants such as urinal catheters, bone implants, etc. to inhibit biofilms originated from pathogenic organisms without using synthetic drugs. Rhamnolipids and sorphorolipids are reported to be potential agents for the inhibition of biofilms formed by Gram-negative and Gram-positive microbes (Sharahi et al., 2019). Few studies reported that cell-associated biosurfactant from Lactobacillus acidophilus inhibits biofilm formation of Proteus vulgaris and S. aureus on polydimethylsiloxane (PDMS)-based implants (Satpute et al., 2019). L. rhamnosusderived biosurfactants cause cell lysis by disrupting the membrane structure, thus can be used as an anti-biofilm agent for multispecies biofilms on silicone devices, i.e., voice prostheses in case of laryngectomy (Tan et al., 2017). The anti-biofilm activity of biosurfactants can augment extensively in combination with caprylic acid that inhibits biofilm formation of $P$. aeruginosa, E. coli, and B. subtilis (Diaz De Rienzo et al., 2016); amphotericin B (AmB) or fluconazole synergistically acts against biofilm formation and preformed biofilm of C. albicans (Haque et al., 2016); and surfactants such as SDS led to the destruction of $P$. aeruginosa PAO1 biofilms (Nguyen et al., 2020).

\section{Antimicrobial Peptides}

AMPs are broad-acting antimicrobial agents widely used in the treatment of both fungal and bacterial biofilms (Pletzer et al., 2016). These peptides disrupt biofilms developed on medical devices such as catheters, artificial valves, stents, dentures, etc. occupied in hospital-acquired infections by $S$. aureus, Klebsiella pneumoniae, P. aeruginosa, Enterococcus faecium, Acinetobacter, and Enterobacter spp. (ESKAPE), and nonESKAPE pathogens (Rajput and Kumar, 2018). AMPs are substitute to traditional antibiotics that are less vulnerable to bacterial resistance by attacking the bacterial cell membrane (Hirt et al., 2018). AMPs occur naturally in humans, animals, plants, and microbes and act on bacterial cell membranes by interacting with membrane phospholipids electrostatically, followed by insertion into membrane, thus killing bacteria. There are reports of synergizing AMPs with antimicrobial compounds to suppress various molecular pathways of biofilm formation (Shahrour et al., 2019).

Amphibian skin is a source for many AMPs effective against various biofilm-causing microorganisms. Yuan et al. (2019) isolated an AMP Japonicin-2LF from Fujian large-headed frog skin secretion (Limnonectes fujianensis) that inhibits MRSA biofilms by membrane permeabilization. Japonicin-2LF behaves like a detergent and eradicates both planktonic and sessile pathogens in biofilms. This property can be exploited to use this peptide as a promising drug candidate in cystic fibrosis patients for the cure of MRSA infection. The main drawback of using AMPs to treat biofilm-based infections is that they are very much prone to degradation by various bacterial proteases.
An AMP from frog skin named esculentin-1a, i.e., Esc (121), and its D-amino acid-containing diastereomer Esc (1-21)-1c inhibited $P$. aeruginosa biofilm formation by its membraneperturbing activity. Previous studies reported that Esc (1-21)1c showed potential activity against chronic lung Pseudomonas infections of cystic fibrosis patients (Casciaro et al., 2019). The introduction of D-amino acids at $\mathrm{Leu}^{14}$ and Ser ${ }^{17}$ into the AMP (esculentin-1a) sequence increases the AMP stability (Casciaro et al., 2019); decreases $P$. aeruginosa swimming, swarming, and twitching motility; and finally inhibits biofilm formation. The peptide inhibits the $P$. aeruginosa biofilm formation by three mechanisms. First, it downregulates the fleN gene that controls the number of flagella in $P$. aeruginosa inhibiting flagellamediated swimming. Second, it decreases the mRNA level of type IV pili biosynthesis genes at very low concentration, i.e., $1 / 8$ MIC, and inhibits the twitching motility of $P$. aeruginosa that is very much essential for micro-colony formation and colonization during biofilm development. Third, it downregulates lasI gene encoding for the quorum-sensing molecule acyl-homoserine lactone (AHL) synthase as well as lasB gene encoding the virulence factors elastase $\operatorname{Las} B$.

In summary, Esc (1-21)-1c lowers the expression of virulence genes and bacterial motility genes, and ultimately prevents biofilm formation. These two anti-pseudomonal peptides esculentin-1a (1-21) and its diastereomer Esc (1-21)-1c have shown promising results in bronchial epithelium repair of cystic fibrosis patients. Cappiello et al. (2019) observed that esculentin repairs bronchial epithelium in cystic fibrosis patients by promoting bronchial cell migration, activating epidermal growth factor receptors, and also increases the secretion of IL-8 for the re-epithelialization process. Besides, the peptide esculentin-1a lowers the expression of mRNA encoding rhamnosyltransferase subunits, i.e., RhlA and RhlB, key enzymes in the biosynthesis of bacterial surfactant rhamnolipids. A recent study by Parducho et al. (2020) reported a specific mode of action of the AMP human Beta-Defensin 2 that increases the roughness of the bacterial surface, alters outer membrane protein profile, and interferes with the transfer of biofilm precursors into the extracellular space (Figure 2).

The melittin peptide of bee venom exhibit antibacterial activity, prevents MRSA systemic infections and initiates the wound healing process in MRSA-infected mice model (Choi et al., 2015). Khozani et al. (2019) studied the efficiency of melittin and found that it degraded about $90-95 \%$ of $P$. aeruginosa biofilm biomass at $50 \mu \mathrm{g}$ concentrations during $24 \mathrm{~h}$. Human cathelicidin LL-37 inhibits bacterial adhesion and biofilm mass of S. epidermidis ATCC 35984 at a very low concentration (Hell et al., 2010). In addition to anti-biofilm activity, LL-37 exhibits immunomodulatory activity such as cellular recruitment (Tjabringa et al., 2006), enhances host adaptive immune responses (Diamond et al., 2009), and modulates inflammatory responses (Mookherjee et al., 2006). The dual property of AMPs to counter bacterial biofilms as well as modulating the host immune system can be exploited to design a novel strategy to combat drug-resistant microbial biofilms.

Parducho et al. (2020) reported the inhibitory property of human Beta-Defensin 2 in $P$. aeruginosa biofilm by inducing 
structural changes, altering outer membrane protein profile and interfering with the transfer of biofilm precursors into the extracellular space. Few natural peptides with anti-biofilm activity and their disadvantages are listed in Table 3. A peptide DRAMP ID: DRAMP18417 derived from the venom of scorpion (Tityus obscurus) has shown promising anti-biofilm activity against Candida spp. and Cryptococcus neoformans strains (Guilhelmelli et al., 2016). These peptides inhibit fungal biofilms at initial adhesion and mature stages, and exhibit minimal hemolytic and cytotoxic activity on erythrocytes and murine peritoneal macrophages.

Pathogens which form the biofilms on the implanted medical devices, human skin, gut, and oral cavities generally communicate through quorum sensing (QS) signals. The quorum sensing inhibiting potential of AMPs from natural sources offers an alternative antibiotic-free approach to overcome biofilmassociated infections. To date, more than 3000 AMPs have been discovered, but only seven of them have been approved by the FDA (Chen and Lu, 2020). There is a severe scarcity of clinical studies on natural AMPs due to their poor performance, cytotoxic and hemolytic activities, unpredicted side effects such as kidney injuries, damage to central nervous systems, etc. The futility of natural AMPs in pre-clinical stages may be due to variations between the clinical setting and their resident conditions. So, clinical research needs to be exaggerated and optimized for the use of these natural anti-biofilm agents against various drugtolerant biofilms. It is essential to exploit the structure of different naturally occurring AMPs to develop novel therapeutic peptides with improved stability and activity in comparison with their natural counterparts.

Efforts have been made to design novel specifically targeted multi-domain AMPs composed of a species-targeting peptide linked to a broad-spectrum antimicrobial killing peptide domain (Sztukowska et al., 2019). C16G2 is one of the first functional specifically targeted AMPs designed by fusion of a 16-mer region of the Streptococcus mutans competence-stimulating peptide (CSP) as the targeting domain, flexible triglycine linker and G2 AMP, a 16-residue fragment of novispirin G10 (Steinstraesser et al., 2002), and a derivative of ovispirin-1 (N-terminal 18 residues of the sheep cathelicidin SMAP29). C16G2 inhibits the biofilm growth of $S$. mutans effectively both in pure culture and in a multispecies community (Guo et al., 2015). This peptide not only kills $S$. mutans but also reduces other species that are metabolically dependent on $S$. mutans and mediates the re-establishment of oral microbiome. This specifically targeted AMP avoids the loss of natural microflora by selectively targeting the pathogens and leaving commensal Streptococci undamaged. C16G2 has completed a single-blind, open-label phase II clinical trial in various varnish and strip formulations (ClinicalTrials.gov Identifier: NCT03196219) among female and male dental subjects.

Similarly, attempts have been made to target only the pathogenic organisms of the biofilm without influencing the normal microflora (Xu et al., 2020). They designed peptides by fusing species-specific enterococcal pheromone cCF10 with a broad-spectrum AMP C6. They proved that incorporation of cCF10 at the $\mathrm{N}$ terminus of C6 drastically increased antimicrobial activity against E. faecalis comparative with C6 alone. They also reported that the hybrid peptides stimulated negligible hemolysis against human RBCs at antimicrobial levels, demonstrating that these fusion peptides could be exploited as potential anti-biofilm agents for clinical implementation.

\section{Therapeutic Strategies Using Natural Products}

The failure of conventional antibiotic therapies indicates that biofilm treatments need auxiliary upgradation (Zhang et al., 2020). Natural anti-biofilm agents selectively exterminate the persistent biofilms and allow the diffusion of antimicrobials into the biofilm matrix. These natural products target various phases of biofilm cycle to degrade the biofilm matrix and finally kills the released cells (Figure 3). A better understanding of the disruption and dispersal mechanism of biofilms will help researchers to design improved anti-biofilm strategies.

A recent study reported that elasnin (an anti-biofilm compound from an actinobacteria Streptomyces mobaraensis DSM 40847) destroyed the matrix in a multispecies biofilm and making them more vulnerable to antibiotics (Long et al., 2020). To improve the current strategies of biofilm inhibition, the concern of the present review is to exploit natural agents for the development of an effective and safe strategy. This review aims to cover some current systems that are being put into practice to disintegrate EPS, quench QS networks, inhibit adhesion, and interrupt biofilm formation (Figure 4).

\section{Extracellular Polymeric Substance (EPS)-Targeting Strategies}

Microbial EPSs secreted by a large variety of microorganisms mainly composed of polysaccharides, structural proteins, and extracellular DNA. The EPS matrix supports microbial adhesion to a surface, aggregation in multilayered biofilms, and functions as a three-dimensional scaffold that provides hydration, digestive capacity, and protection against antimicrobial compounds, antibiotics, and host effecter molecules (Flemming et al., 2016a). The EPS matrix can actively alter nutrient gradients and portray pathogenic environments that contribute to tolerance and virulence traits. So, many therapeutic strategies are designed to target the EPS matrix to eliminate biofilms, disaggregate bacteria, and interrupt the pathogenic environment. Many bacterial enzymes and secondary metabolites interfere with the quorum sensing mechanisms of pathogenic bacteria, thus disrupting the biofilm formation (Khan et al., 2019). Biofilm matrixdegrading enzymes such as beta- $N$-acetylglucosaminidase and dispersin B secreted by the Gram-negative periodontal pathogen Actinobacillus actinomycetemcomitans disintegrate mature biofilms of Staphylococcus epidermidis. Cocktail of two EPS-degrading enzymes, DNase I and dispersin B, has been found to inhibit staphylococcal skin colonization and remove pre-attached $S$. aureus cells from the skin and enhance their povidone-iodine susceptibility in an in vivo pig skin colonization model (Kaplan et al., 2018). Hogan et al. (2017) reported that lysostaphin was an effective antistaphylococcal agent and its therapeutic efficacy can be improved 
TABLE 3 | Sources and effects of AMPS.

\begin{tabular}{|c|c|c|c|c|c|c|c|}
\hline $\begin{array}{l}\text { Name of } \\
\text { AMPs }\end{array}$ & Amino acid sequence & Net charge & 3D structure & Source & Effects on biofilm & Disadvantages & References \\
\hline Japonicin-2LF & $\begin{array}{l}\text { FIVPSIFLLKK } \\
\text { KAFCIALKKC }\end{array}$ & 4 & Helix & Frog skin secretion & $\begin{array}{l}\text { Eradicates the } \\
\text { methicillin-resistant } \\
\text { S. aureus biofilm matrix as } \\
\text { well as kills all the sessile } \\
\text { bacteria }\end{array}$ & $\begin{array}{l}\text { Futile against } P \text {. aeruginosa biofilms. } \\
\text { The anti-biofilm activity concealed by } \\
\text { the changes in LPS contents and cell } \\
\text { wall structure of microorganisms }\end{array}$ & Yuan et al., 2019 \\
\hline $\begin{array}{l}\text { Dermaseptin- } \\
\text { PT9 }\end{array}$ & $\begin{array}{l}\text { GLWSKIKDAAKT } \\
\text { AGKAALGFVNEMV }\end{array}$ & 2 & Helix & Frog skin secretion & $\begin{array}{l}\text { Inhibits the biofilm } \\
\text { formation of } S \text {. aureus, } \\
\text { MRSA, and } E \text {. coli }\end{array}$ & $\begin{array}{l}\text { More potent activity against } \\
\text { Gram-negative bacteria }\end{array}$ & Li et al., 2019 \\
\hline $\begin{array}{l}\text { Phylloseptin- } \\
\text { PTa }\end{array}$ & $\begin{array}{l}\text { FLSLIPAA } \\
\text { ISAVSALANHF }\end{array}$ & 2 & Helix & Frog skin secretion & $\begin{array}{l}\text { More potent against } \\
\text { S. aureus biofilm }\end{array}$ & $\begin{array}{l}\text { Anti-biofilm activity changed by the } \\
\text { hydrophobicity, charges and } \alpha \text {-helicity } \\
\text { of the peptides }\end{array}$ & Liu et al., 2017 \\
\hline $\begin{array}{l}\text { Moronecidin- } \\
\text { like }\end{array}$ & $\begin{array}{l}\text { FFRNLWKGAK } \\
\text { AAFRAGHAAWRA }\end{array}$ & 6 & Unknown & Seahorse & $\begin{array}{l}\text { Inhibits surface attachment } \\
\text { of } S \text {. aureus biofilm }\end{array}$ & $\begin{array}{l}\text { More effectual against Gram-positive } \\
\text { bacteria than Gram-negative bacteria } \\
\text { The outer membrane proteins of } \\
\text { Gram-negative bacteria may hinder } \\
\text { translocation of AMPs through the } \\
\text { outer membrane }\end{array}$ & $\begin{array}{l}\text { Mohammadi et al., } \\
2018\end{array}$ \\
\hline Mastoporan & $\begin{array}{l}\text { LNLKALL } \\
\text { AVAKKIL }\end{array}$ & 4 & Helix & $\begin{array}{l}\text { European hornet } \\
\text { venom }\end{array}$ & $\begin{array}{l}\text { Suppresses biofilm } \\
\text { formation by } S \text {. aureus and } \\
P \text {. aeruginosa }\end{array}$ & $\begin{array}{l}\text { Release histamine from mammalian } \\
\text { mast cells may lead to an immune } \\
\text { response }\end{array}$ & Chen et al., 2018 \\
\hline Melittin & $\begin{array}{l}\text { GIGAVLKVLTTG } \\
\text { LPALISWIKRKRQQ }\end{array}$ & 6 & Helix & Honeybee venom & $\begin{array}{l}\text { Induce disintegration of the } \\
\text { MDR } P \text {. aeruginosa and } \\
\text { degrades the biofilm }\end{array}$ & $\begin{array}{l}\text { The toxicity of melittin on normal cells is } \\
\text { a disadvantage for clinical applications } \\
\text { (in case of third-degree burn patients, } \\
\text { all three layers of skin are destroyed, so } \\
\text { cytotoxicity of melittin hardly limits its } \\
\text { applications) }\end{array}$ & Khozani et al., 2019 \\
\hline NA-CATH & $\begin{array}{l}\text { KRFKKFFKKLKKNSV } \\
\text { KKRAKKFFKKYKVVIGVTFPF }\end{array}$ & 15 & Helix & $\begin{array}{l}\text { Chinese cobra } \\
\text { (Naja atra) }\end{array}$ & $\begin{array}{l}\text { Prevent biofilm formation of } \\
\text { Burkholderia thailandensis }\end{array}$ & $\begin{array}{l}\text { The small size of the peptide restricts } \\
\text { its large-scale synthesis }\end{array}$ & $\begin{array}{l}\text { Blower et al., } 2015 \\
\text { de Barros et al., } \\
2019\end{array}$ \\
\hline $\begin{array}{l}\text { Defensin } \\
\text { ZmD32 }\end{array}$ & $\begin{array}{l}\text { RTCQSQSHRFRGPCLRRS } \\
\text { NCANVCRTEGFPGG } \\
\text { RCRGFRRRCFCTTHC }\end{array}$ & 12 & $\begin{array}{l}\text { Combine Helix } \\
\text { and Beta } \\
\text { structure }\end{array}$ & Corn, Zea mays & $\begin{array}{l}\text { Active against Candida } \\
\text { albicans biofilms }\end{array}$ & $\begin{array}{l}\text { Anti-biofilm activity of many defensins } \\
\text { lost in the presence of salt }\end{array}$ & $\begin{array}{l}\text { Kerenga et al., } \\
2019\end{array}$ \\
\hline Capsicumicine & $\begin{array}{l}\text { RSCQQQIQQ } \\
\text { AQQLSSCQQYLKQ }\end{array}$ & - & Unknown & $\begin{array}{l}\text { Red pepper, } \\
\text { Capsicum } \\
\text { bacattum }\end{array}$ & $\begin{array}{l}\text { Prevents the establishment } \\
\text { of } S \text {. epidermidis biofilm by } \\
\text { matrix anti-assembly (MAA) } \\
\text { mechanism }\end{array}$ & NS & $\begin{array}{l}\text { Von Borowski et al., } \\
2020\end{array}$ \\
\hline $\begin{array}{l}\text { Rhesus theta } \\
\text { defensin-1 }\end{array}$ & GFCRCLCRRGVCRCICTR & 5 & Beta & Monkey leukocytes & $\begin{array}{l}\text { Active against established } \\
\text { C. albicans biofilms }\end{array}$ & $\begin{array}{l}\text { Most of the host defense peptides } \\
\text { exhibit undesirable pro-inflammatory } \\
\text { properties and low bioavailability }\end{array}$ & Basso et al., 2019 \\
\hline
\end{tabular}

NS, not specified. 


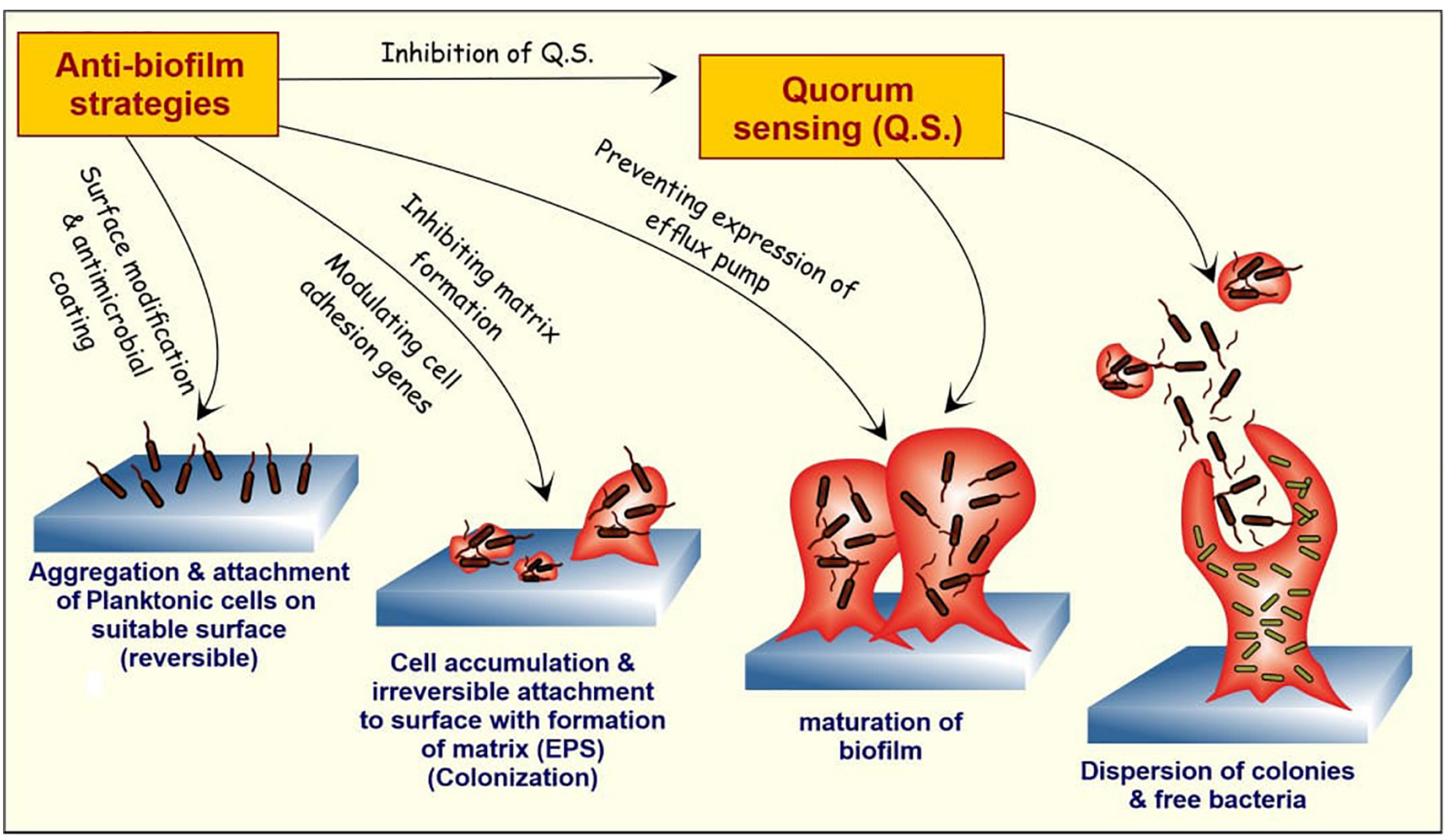

FIGURE 3 | The stages of biofilm formation and potential targets for anti-biofilm agents. The bacterial cells in humans attach to the matrix-forming proteins by forming a covalent linkage with peptidoglycan structure or by non-covalent attachment. With attachment and aggregation of a sufficient number of cells, the formation of EPS matrix takes place, and the attachment now becomes resistant to external repulsive forces. With the maturation of biofilm, the cells within the bulk structure start further communication with each other and start secreting specialized proteins and DNA, and some of them are involved in the formation of the efflux pump. At last, the dispersion of free planktonic cells from the formed biofilm further promotes the formation of new biofilms in the periphery. The natural anti-biofilm compounds can attack at one or different stages of biofilm formation and development, thus inhibiting it.

in combination with antibiotics. Few biofilm-degrading enzymes with their mechanism of biofilm inhibition are summarized in Table 4.

The existing enzymes which have less catalytic activity can enhance their catalytic properties against the biofilms by modeling and engineering approach. The site-directed mutational analysis is considered as another approach to modulate the biofilm-inhibiting properties of the enzymes. Thus, broad-spectrum enzymes/peptides, as well as secondary compounds, must be isolated from bacteria for bioprospection, which can target a broad range of QS signaling molecules and structural part of the biofilms. The complete elimination of heterogeneous biofilms needs amalgamation of hydrolytic enzymes that can degrade proteins, polysaccharides, eDNA, and QS molecules (Yuan et al., 2020). The application of matrixdegrading enzymes in biofilm control is presently limited due to cost, handling procedures, and low industrial accessibility (Nahar et al., 2018).

\section{Quorum Sensing Targeting Strategies}

Prevention of cell-to-cell communication (quorum sensing) is an efficient strategy to restrain biofilm formation (Sharahi et al., 2019). It is reported that metalloprotein AHL-lactonase from the cell-free extract of endophytic Enterobacter species causes degradation of $N$ - AHL, thus significantly inhibiting biofilm formation by Aeromonas hydrophila (Shastry et al., 2019). The result of a recent study reported that Lactobacillus crustorum
ZHG 2-1 as novel quorum-quenching bacteria degrade $N$ 3-oxododecanoyl- $d l$-homoserine lactone (3-oxo-C12-HSL) and $N$-butyryl- $d l$-homoserine lactone (C4-HSL) and functions as an anti-biofilm agent against $P$. aeruginosa (Cui et al., 2020). Several quorum quenching (QQ) enzymes and compounds have been reported. The majority of these QQ molecules have been isolated from natural sources (LaSarre and Federle, 2013). The result of a recent study revealed QS inhibitory potentials of ethyl acetate extracts from cell-free supernatants and cells of Natrinemaversi forme against $P$. aeruginosa biofilm (Başaran et al., 2020). Many QS inhibitors from plant-based natural products have been identified (Caceres et al., 2020; Zhong et al., 2020) and proposed to be effective in future biofilm targeting strategies. The role of natural anti-biofilm agents in the inhibition of quorum sensing molecules is mentioned in the first part of the review. Here, we attempted to explain their effect on the disruption of QS mechanism. These anti-biofilm agents disrupt quorum-sensing systems mainly in two ways: (1) inhibition and degradation of signal molecules, and (2) mimicking the signal molecules for inhibition of their binding to corresponding receptors (Kalia, 2013).

On the other hand, quorum quenchers are usually species specific; therefore, a combination of quenchers is required to eliminate mixed-species biofilms. Ajoene, a sulfur-rich molecule from garlic, decreases the expression of small regulatory RNAs (sRNAs) in both Gram-negative ( $P$. aeruginosa) and Grampositive ( $S$. aureus) bacteria. Ajoene is the first compound to 


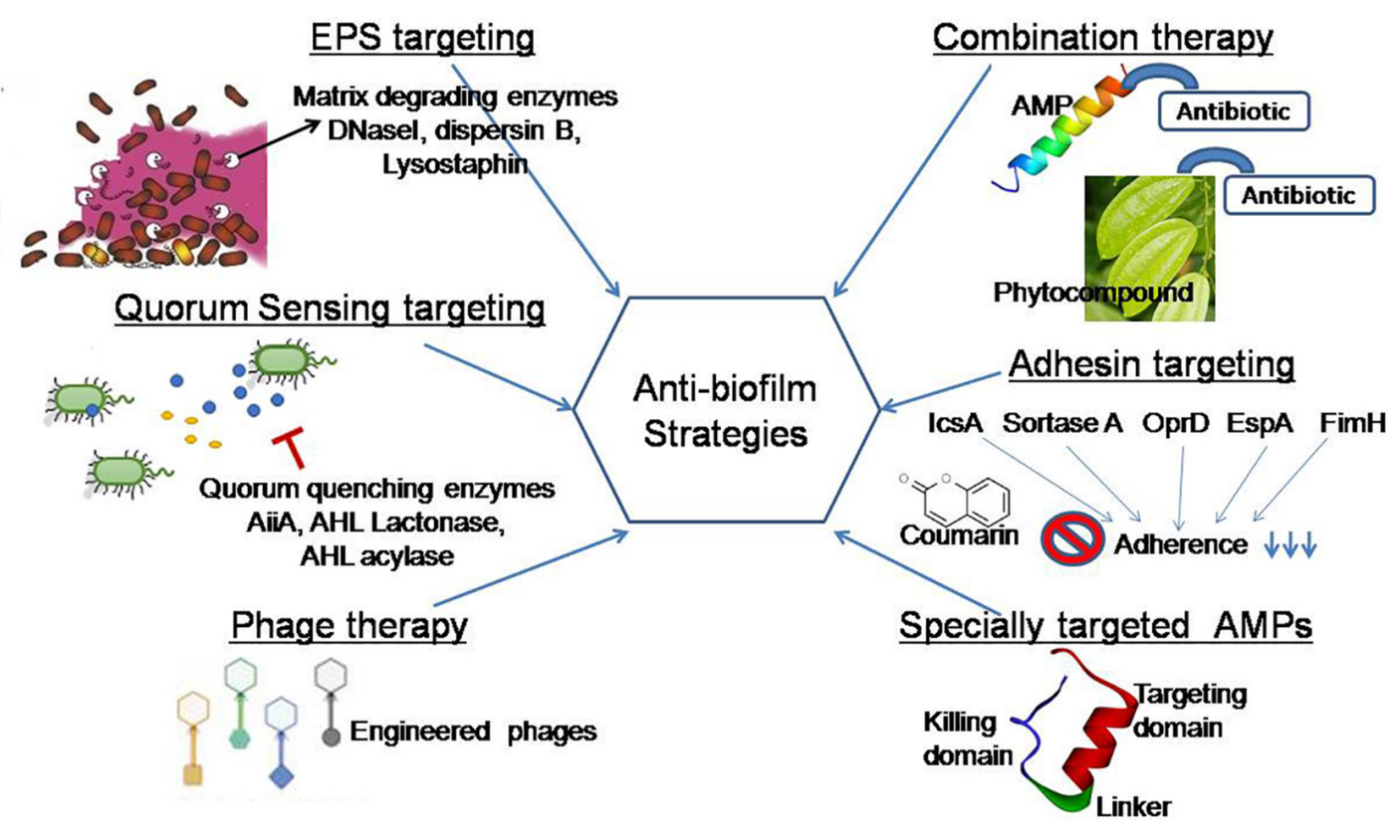

FIGURE 4 | Graphical representation of anti-biofilm strategies covered in this review. EPS targeting: EPS matrix is targeted by matrix-degrading enzymes (DNasel, dispersin B, lysostaphin) that inhibit microbial adhesion to a surface. Quorum sensing targeting: This strategy focused on the use of natural agents that block cell-cell communication in preformed biofilms and regulate virulence factor production (Shastry et al., 2019). Phage therapy: Engineered phages degrade the matrix exopolysaccharide by producing polysaccharide depolymerase enzymes. Specially targeted AMPs: This novel strategy targets in a species-specific manner due to the presence of species targeting peptides (Xu et al., 2020). Adhesin targeting: Phytocompounds target adhesin proteins and blocked biofilm formation at the beginning (Adnan et al., 2020). Combination therapy: Natural anti-biofilm agents function effectively in a combined approach in comparison with its single use.

be identified to target broad-spectrum range quorum sensing inhibitors, i.e., lowers the RNAIII expressions in S. aureus (Scoffone et al., 2019) and RsmY and RsmZ in P. aeruginosa (Jakobsen et al., 2017). Ajoene lowered expression of small regulatory RNAs ( $r s m Y$ and $r s m Z$ ) in $P$. aeruginosa as a result of which it represses translation of biofilm matrix polysaccharides Pel and Psl and the type VI secretion system (T6SS). The T6SS in $P$. aeruginosa plays an essential role in the expression of various virulence factors and greatly concerned with the biofilm formation, pyocyanin production, and pathogenicity of the organism (Li et al., 2020). These findings suggest that T6SS may be a prospective therapeutic target against $P$. aeruginosa infections. Jakobsen et al. (2017) also found that ajoene lowers the expression of regulatory RNA and RNAIII, and inhibits the expression of RNAIII-dependent virulence factors such as lipase, protease, and $\alpha$-hemolysinin in S. aureus. Emodin (1, 2, 8-trihydroxy-6-methyl anthraquinone), an anthraquinone derivative identified from Rheum palmatum (Chinese rhubarb) and Polygonum cuspidatum (Asian knotweed), effectively downregulated luxS gene in Streptococcus suis (Yang et al., 2015) and icaA, sarA, and agrA genes in S. aureus (Yan et al., 2017).

The anti-biofilm peptide Human Cathelicidin LL-37 affects the bacterial cell signaling system and inhibits $P$. aeruginosa biofilm formation at $0.5 \mu \mathrm{g} / \mathrm{ml}$ by downregulating genes of the QS system (Di Somma et al., 2020). AMPs interact with membranes of bacteria and, in turn, activate genes that are regulated through QS. These QS autoinducers passed through the plasma membrane with the help of membrane vesicles. This process, in turn, activates the expression of virulence genes associated with QS. Autoinducers help in interspecies signal transduction; one interesting autoinducer is small autoinducing peptide molecule (AIP) from Lactobacilli that inhibits the viability of microbes and acts as a suppressor of bacteriotoxin production. During the process of suppression of exotoxin production, they interfere with the agr QS system (Vasilchenko and Rogozhin, 2019). However, quorum quenchers can be rinsed away during biofilm formation that makes limited uses of these inhibitors confined to small areas of biofilm only (Koo et al., 2017). Thus, combination approach of these inhibitors along with other strategies leads to a novel therapeutic approach.

\section{Phage Therapy}

Lytic bacteriophages have been used as an effective therapeutic strategy to remove biofilm cells. A recently published study proved that two lytic phages vB_SauM_ME18 and vB_SauM_ME126 are potential natural antimicrobials for inhibiting biofilm of MDR S. aureus (Gharieb et al., 2020). Recent investigations have shown that (engineered) phage-derived enzymes-polysaccharide depolymerase or peptidoglycandegrading enzymes-are promising therapeutic anti-biofilm candidates (Reuter and Kruger, 2020). Phage therapy got its first FDA approval in the year 2019 in which patients received phage treatment at the School of Medicine, University of California San Diego (UCSD) phage therapy center (Pires et al., 2020). The administration of phage therapy is active only in a few 
TABLE 4 | Biofilm-degrading enzymes against various human pathogens.

\begin{tabular}{|c|c|c|c|c|}
\hline Enzymes & Source & Pathogenic bacteria & $\begin{array}{l}\text { Molecular mechanism of biofilm } \\
\text { inhibition }\end{array}$ & References \\
\hline Serine protease, Esp & Staphylococcus epidermidis & Staphylococcus aureus & $\begin{array}{l}\text { Esp degrades S. aureus surface } \\
\text { proteins and host receptors }\end{array}$ & Sugimoto et al., 2013 \\
\hline Lysostaphin & Staphylococcus simulans & $\begin{array}{l}\text { Methicillin-resistant Staphylococcus } \\
\text { aureus (MRSA) }\end{array}$ & $\begin{array}{l}\text { Cleaves the pentaglycine cross-bridges } \\
\text { of peptidoglycan and destroyed EPS } \\
\text { matrix }\end{array}$ & $\begin{array}{l}\text { Algburi et al., } 2017 \\
\text { Hogan et al., } 2017\end{array}$ \\
\hline$\alpha$-Amylase & Bacillus subtilis S8-18 & $\begin{array}{l}\text { Methicillin-resistant Staphylococcus } \\
\text { aureus (MRSA) }\end{array}$ & $\begin{array}{l}\text { Degrades the preform mature biofilm by } \\
\text { disrupting EPS matrix }\end{array}$ & Kalpana et al., 2012 \\
\hline Cellulase & $\begin{array}{l}\text { Penicillium funiculosum } \\
\text { Trichoderma reesei }\end{array}$ & Pseudomonas aeruginosa & $\begin{array}{l}\text { Decreases the adhesion of cells to the } \\
\text { surface and polysaccharide matrix }\end{array}$ & Loiselle and Anderson, 2003 \\
\hline Cellulase & $\begin{array}{l}\text { Aspergillus niger } \\
\text { Bacillus sp. DGV19 }\end{array}$ & Burkholderia cepacia & Degrades the exopolysaccharide & Rajasekharan and Ramesh, 2013 \\
\hline Alginate lyase & Bacillus circulans ATCC 15518 & Pseudomonas aeruginosa & Degrades the exopolysaccharide & Alkawash et al., 2006 \\
\hline Hyaluronan & Streptococcus equi & Staphylococcus aureus & NS & Ibberson et al., 2016 \\
\hline $\begin{array}{l}\text { Cysteine, histidine dependent } \\
\text { amidohydrolase/peptidase } \\
\mathrm{CHAP}_{K}\end{array}$ & Myoviridae staphylococcal Phage K & Staphylococcus aureus & $\begin{array}{l}\text { Cleaves the peptide bond involving } \\
\text { D-alanine and the first glycine in the } \\
\text { pentaglycine cross-bridge of } \\
\text { Staphylococcal cell wall peptidoglycan }\end{array}$ & Fenton et al., 2013 \\
\hline Endolysin LysH5 & Phage vB_SauS-philPLA88 & $\begin{array}{l}\text { Staphylococcus aureus, } \\
\text { Staphylococcus epidermidis }\end{array}$ & Anti-persister agents & Gutierrez et al., 2014 \\
\hline DNase I & Human stratum corneum & $\begin{array}{l}\text { Pseudomonas aeruginosa, } \\
\text { Staphylococcus aureus }\end{array}$ & $\begin{array}{l}\text { Degradation of extracellular DNA } \\
\text { prevents the formation of biofilm }\end{array}$ & Eckhart et al., 2007 \\
\hline DNase I and Proteinase $\mathrm{K}$ & NS & $\begin{array}{l}\text { Actinomyces oris, Fusobacterium } \\
\text { nucleatum, Streptococcus mutans, } \\
\text { Streptococcus oralis, and Candida } \\
\text { albicans }\end{array}$ & $\begin{array}{l}\text { Affected the structural integrity of the } \\
\text { biofilms by removal of eDNA and } \\
\text { extracellular proteins }\end{array}$ & Karygianni et al., 2020 \\
\hline Trypsin & Pancreatic serine endoprotease & Pseudomonas aeruginosa & $\begin{array}{l}\text { Destroy the protein contents of the } \\
\text { biofilm matrix }\end{array}$ & Banar et al., 2016 \\
\hline
\end{tabular}

NS, not specified. 
countries, and its clinical use faces many challenges such as the establishment of phage banks with characterized phages; safety, stability, and quality of phage preparations during production; and the evolution of bacterial resistance to phages.

\section{Combination Therapy}

Natural anti-biofilm agents sensitize antibiotics and established to be more effective when used in amalgamation (Zhang et al., 2020). They also reported that the combined application of sodium houttuyfonate and levofloxacin act in a better manner to inhibit biofilm formation. Sodium houttuyfonate, a plantderived anti-neuropeptide, effectively disrupts biofilm dispersion in P. aeruginosa (Wang et al., 2019). Naringin, a flavanone glycoside extracted from citrus and grapefruits, was found to be more effective against $P$. aeruginosa biofilms in comparison with individual treatment of marketed antibiotics ciprofloxacin and tetracycline (Dey et al., 2020). Naringin depletes biofilm EPS and facilitates the diffusion of antimicrobials, reduces pellicle formation, and decreases the flagellar movement of bacteria on catheter surfaces.

Zhou et al. (2018) tested the effect of hordenine, a polyphenolic compound from barley, on biofilm formation individually as well as in combination with an aminoglycoside antibiotic, netilmicin. The results were promising, showing up to $88 \%$ reduction in $P$. aeruginosa $\mathrm{PAO} 1$ biofilms by a combination of hordenine and netilmicin, which was significantly better than the effect of any of the individual treatments. It indicates that the drug-herb combination therapy may be explored for effective anti-biofilm formulation opportunities. The SEM study showed a reduction in the thickness of the biofilm layer and the disruption of its architecture. The results of the study also revealed downregulation in the expression of quorum-sensing regulatory genes, especially las $R$, by hordenine as the possible mechanism against biofilm development. Actinobacterial compounds from different microbial species have also shown potential anti-biofilm activity against different pathogenic bacteria by interrupting the cell surface and interaction between cells (Azman et al., 2019). Studies focusing on a combination of more than one natural antibiofilm compound/s from different sources or acting on different stages of biofilm development will further help in developing more effective agents targeting biofilms. Moreover, the selection of a more effective compound is also necessary as the efficacy of natural compounds against biofilm development is different against different strains of bacteria.

\section{Anti-biofilm Biomaterial Therapy}

The adhesion of biofilm-associated pathogenic organisms on implant surfaces restricts their clinical applications, so many attempts have been made by various researchers to coat biomaterial as a preventive strategy. Natural polymer-based surface coatings, such as anti-adhesive coatings of algal polysaccharide ulvan, dextran, and dermatan sulfate, and antimicrobial-releasing polysaccharide coatings etc. have been popularized during the last decade (Junter et al., 2016). A recent report on anti-adhesive CyanoCoating (a coating from marine cyanobacterium Cyanothece sp. CCY 0110) was exploited as a defensive strategy against a broader range of microbes (especially Proteus mirabilis, E. coli, and C. albicans biofilms) in catheter-linked urinary tract infections (Costa et al., 2020). The molecular mechanism to prevent the cell adhesion is that the hydrophilic polysaccharides form a hydration layer on the surface which acts as a physical barrier (Damodaran and Murthy, 2016) and prevents cell adhesion to the surface. Calcium phosphate cement and hydroxyapatite are the calcium phosphate materials that are used as a bone coating to avoid infections of biofilm, but they have various limitations in clinical trials (Pan et al., 2018). Implant-related infections can be avoided by chitosan hydrogel coatings which prevent bacterial adhesion and biofilm formation due to membrane leaching (Pan et al., 2018). A group of natural polymers were used as drug transporters in various forms like fibers, strips, gels (Badam gum, Karaya gum, chitosan), films (chitosan), nanoparticles, and microparticles which help in delivering antibiotics to the targeted site mainly for periodontal biofilm-forming pathogens (Chi et al., 2019). Nisin, an FDA-approved AMP, acts as anti-biofilm agent synergistically with conventional antibiotics against methicillin-resistant Staphylococcus aureus, Streptococcus pneumoniae, Enterococci, and Clostridium difficile (Shin et al., 2016). A recent report stated that nisin in conjugation with gellan gum, a biocompatible polysaccharide, shows promising results in biomaterial research (Peng et al., 2020).

\section{CONCLUSION AND FUTURE DIRECTIONS}

The occurrence of many biofilm-based human infections and their multiple antimicrobial resistance is a major concern in medicine and human health. The elevated rate of resistance to antibiotics in biofilm leads to the discovery and characterization of novel natural anti-biofilm agents. This review describes different types of phytocompounds, antimicrobial peptides, and biosurfactants that exhibit promising biofilm-inhibiting ability. Natural anti-biofilm agents could be effectively used to deal with certain surgeries and diseases where there is a possibility of untraceable infection sites like bone, dental, eye lenses, and breast implants. These agents of natural origin are structurally and functionally more diverse in comparison with conventional antibiotics. The structure and function of natural anti-biofilm agents from various sources have been exploited to develop numerous advanced therapeutic strategies showing increased activity, stability, and reliability. Here, we continue to analyze the efficacy of specially targeted AMPs against drug-tolerant pathogenic biofilms without disturbing the natural microflora.

Natural products, mainly phytochemicals, as anti-biofilm agents have been studied more in in vitro and in vivo conditions, but not a single FDA-approved drug was developed despite huge efforts. Most of them failed in phase II and phase III clinical trials (Lu et al., 2019). The possible reason for this failure may be the availability of the compound in humans after administration which decreases the efficacy of the compounds. One possible solution to this problem is a combination of strategies like antibiotics, along with natural anti-biofilm agents for better results. Combination therapy of natural agents with commercial 
antibiotics needs urgent exploitation in the future to advance anti-biofilm activity. Quorum quenchers of natural origin along with antibiotics can be a novel lead for species-specific biofilm destruction, and it has a promising utilization aspect in biomedical industries. More studies should be directed in this regard for converting the novel anti-biofilm phytocompounds into drugs. Most of the clinical studies on natural anti-biofilm compounds as reported in http://clinicaltrials.gov/are focused on oral biofilms, and very few are related to urinary tract infections (Lu et al., 2019). Further studies in in vivo models and clinical trials are needed to test the efficiency of natural anti-biofilm agents in the future.

The review also explains the quorum quenching molecules and EPS-degrading enzymes of natural origin along with their mode of action on various biofilms. The mechanism of action of various natural agents against biofilm remains unknown. More studies on the mode of action may help to identify novel antibiofilm agents. Anti-adhesin strategy can be a novel strategy for biofilm treatments on a broad range of bacteria as it targets and prevents attachment of bacteria to the cell surface. Very few studies have been made in this area, so future research in targeting biofilm in the direction of adhesin proteins may lead to the discovery of unique natural anti-biofilm agents. Pili and curli gene expression regulating phytocompounds can control biofilm formation. More work in these directions or a combination of phytocompound which has anti-adhesin properties may be a better therapeutic strategy for biofilmrelated ailments.

The failure of natural medicines in clinical trials can be checked by rigorous quality control. The discovery of accurate markers that are sensitive and stable can resolve the problem and

\section{REFERENCES}

Abdel-Aziz, M. M., Al-Omar, M. S., Mohammed, H. A., and Emam, T. M. (2020). In-vitro and Ex-vivo anti-biofilm activity of a lipopeptide biosurfactant produced by the Entomopathogenic Beauveria bassiana strain against Microsporum canis. Microorganisms 8:232. doi: 10.3390/ microorganisms 8020232

Abdelli, F., Jardak, M., Elloumi, J., Stien, D., Cherif, S., Mnif, S., et al. (2019). Antibacterial, anti-adherent and cytotoxic activities of surfactin (s) from a lipolytic strain Bacillus safensis F4. Biodegradation 30, 287-300. doi: 10.1007/ s10532-018-09865-4

Abdollahi, S., Tofighi, Z., Babaee, T., Shamsi, M., Rahimzadeh, G., Rezvanifar, H., et al. (2020). Evaluation of anti-oxidant and anti-biofilm activities of biogenic surfactants derived from Bacillus amyloliquefaciens and Pseudomonas aeruginosa. Ira. J. Pharm. Res. 19, 115-126. doi: 10.22037/ijpr.2020.110 1033

Adnan, M., Patel, M., Deshpande, S., Alreshidi, M., Siddiqui, A. J., Reddy, M. N., et al. (2020). Effect of Adiantum philippense extract on biofilm formation, adhesion with its antibacterial activities against foodborne pathogens, and characterization of bioactive metabolites: an in vitroin silico approach. Front. Microbiol. 11:823. doi: 10.3389/fmicb.2020. 00823

Algburi, A., Comito, N., Kashtanov, D., Dicks, L. M., and Chikindas, M. L. (2017). Control of biofilm formation: antibiotics and beyond. Appl. Environ. Microbiol. 83, e2508-e2516. doi: 10.1128/AEM.02508-16

Alkawash, M. A., Soothill, J. S., and Schiller, N. L. (2006). Alginate lyase enhances the antibiotic killing of mucoid Pseudomonas aeruginosa in biofilms. Apmis 114, 131-138. doi: 10.1111/j.1600-0463.2006.apm_356.x help in better quality control of natural anti-biofilm agents. It is a significant challenge faced by natural product research for the discovery of useful QC markers as natural compounds have a very complex structural lattice (Zhang et al., 2020). Drug efficacy of natural compounds is mainly based on network pharmacology methods. As a result, more research in this direction can enhance success rate in clinical trials at the final stage. Novel natural anti-biofilm agents in therapeutics may be possible if rigorous studies will be done in quality control, pharmacokinetic and pharmacodynamic co-relationships (PK-PD), and PK-PD interactions with metabolomics of host for evaluation of safety and efficacy of the drug.

\section{AUTHOR CONTRIBUTIONS}

AP, RM, SD, MS, and SS drafted the manuscript. AP, RM, and $\mathrm{JK}$ were responsible for preparing the tables and figures in the manuscript. AP and RM equally contributed to the development of this manuscript. SS assisted to revise the manuscript. All the authors read and approved the final manuscript.

\section{ACKNOWLEDGMENTS}

The authors gratefully acknowledge Prof. Hans-Curt Flemming, Biofilm Centre, Faculty of Chemistry, University of DuisburgEssen, Essen, Germany, and Visiting Professor, Singapore Centre for Environmental Life Sciences Engineering (SCELSE), Singapore for his invaluable conceptual and technical advice to this work.

Arita-Morioka, K. I., Yamanaka, K., Mizunoe, Y., Tanaka, Y., Ogura, T., and Sugimoto, S. (2018). Inhibitory effects of Myricetin derivatives on curlidependent biofilm formation in Escherichia coli. Sci. Rep. 8:8452. doi: 10.1038/ s41598-018-26748-z

Ashitha, A., Radhakrishnan, E. K., and Jyothis, M. (2020). Characterization of biosurfactant produced by the endophyte Burkholderia sp. WYAT7 and evaluation of its antibacterial and anti-biofilm potentials. J. Biotechnol. 313, 1-10. doi: 10.1016/j.jbiotec.2020.03.005

Azman, A. S., Mawang, C. I., Khairat, J. E., and AbuBakar, S. (2019). Actinobacteria-a promising natural source of anti-biofilm agents. Int. Microbiol. 22, 403-409. doi: 10.1007/s10123-019-00066-4

Balan, S. S., Kumar, C. G., and Jayalakshmi, S. (2016). Pontifactin, a new lipopeptide biosurfactant produced by a marine Pontibacter korlensis strain SBK-47: purification, characterization and it's biological evaluation. Process Biochem. 51, 2198-2207. doi: 10.1016/j.procbio.2016.09.009

Banar, M., Emaneini, M., Satarzadeh, M., Abdellahi, N., Beigverdi, R., van Leeuwen, W. B., et al. (2016). Evaluation of mannosidase and trypsin enzymes effects on biofilm production of Pseudomonas aeruginosa isolated from burn wound infections. PLoS One 11:e0164622. doi: 10.1371/journal.pone.01 64622

Başaran, T. I., Berber, D., Gökalsın, B., Tramice, A., Tommonaro, G., Abbamondi, G. R., et al. (2020). Extremophilic Natrinema versiforme against Pseudomonas aeruginosa quorum sensing and biofilm. Front. Microbiol. 11:79. doi: 10.3389/ fmicb.2020.00079

Basso, V., Tran, D. Q., Schaal, J. B., Tran, P., Eriguchi, Y., Ngole, D., et al. (2019). Rhesus Theta Defensin 1 promotes long term survival in Systemic Candidiasis by host directed mechanisms. Sci Rep. 9:16905. doi: 10.1038/s41598-01953402-z 
Blower, R. J., Barksdale, S. M., and Van Hoek, M. L. (2015). Snake cathelicidin NA-CATH and smaller helical antimicrobial peptides are effective against Burkholderia thailandensis. PLoS Negl. Trop. Dis. 9:e0003862. doi: 10.1371/ journal.pntd.0003862

Boles, B. R., and Horswill, A. R. (2008). Agr-mediated dispersal of Staphylococcus aureus biofilms. PLoS Pathog. 4:e1000052. doi: 10.1371/journal.ppat.1000052

Borghi, E., Borgo, F., and Morace, G. (2016). Fungal biofilms: Update on resistance. Adv. Exp. Med. Biol. 931, 37-47. doi: 10.1007/5584_2016_7

Branco-de-Almeida, L. S., Murata, R. M., Franco, E. M., dos Santos, M. H., de Alencar, S. M., and Koo, H. (2011). Effects of 7-epiclusianone on Streptococcus mutans and caries development in rats. Planta Med. 77, 40-45. doi: 10.1055/s0030- 1250121

Branda, S. S., Vik, S., Friedman, L., and Kolter, R. (2005). Biofilms: the matrix revisited. Trends Microbiol. 13, 20-26. doi: 10.1016/j.tim.2004.11.006

Caceres, M., Hidalgo, W., Stashenko, E., Torres, R., and Ortiz, C. (2020). Essential oils of aromatic plants with antibacterial, anti-biofilm and antiquorum sensing activities against pathogenic bacteria. Antibiotics 9:147. doi: 10.3390/antibiotics 9040147

Carneiro, V. A., dos Santos, H. S., Arruda, F. V. S., Bandeira, P. N., Albuquerque, M., Pereira, M. O., et al. (2011). Casbane diterpene as a promising natural antimicrobial agent against biofilm-associated infections. Molecules 16, 190 201. doi: 10.3390/molecules 16010190

Cappiello, F., Ranieri, D., Carnicelli, V., Casciaro, B., Chen, H. T., Ferrera, L., et al. (2019). Bronchial epithelium repair by Esculentin-1a-derived antimicrobial peptides: involvement of metalloproteinase- 9 and interleukin-8, and evaluation of peptides' immunogenicity. Sci Rep. 9:18988. doi: 10.1038/s41598-019-55426$\mathrm{x}$

Casciaro, B., Cappiello, F., Loffredo, M. R., Ghirg, F., and Mangoni, M. L. (2019). The Potential of frog skin peptides for anti-Infective therapies: the Case of Esculentin-1a (1-21) NH2. Curr. Med. Chem. 27, 1405-1419. doi: 10.2174/ 0929867326666190722095408

Cegelski, L., Pinkner, J. S., Hammer, N. D., Cusumano, C. K., Hung, C. S., Chorell, E., et al. (2009). Small-molecule inhibitors target Escherichia coli amyloid biogenesis and biofilm formation. Nat. Chem. Biol. 5, 913-919. doi: 10.1038/ nchembio. 242

Ceresa, C., Rinaldi, M., Chiono, V., Carmagnola, I., Allegrone, G., and Fracchia, L. (2016). Lipopeptides from Bacillus subtilis AC7 inhibit adhesion and biofilm formation of Candida albicans on silicone. Anton. Van Leeuw. 109, 1375-1388. doi: $10.1007 /$ s10482-016-0736-Z

Characklis, W. G. (1973). Attached microbial growths - I. Attachment and growth. Water Res. 7, 1113-1127. doi: 10.1016/0043-1354(73)90066-3

Chen, C. H., and Lu, T. K. (2020). Development and challenges of antimicrobial peptides for therapeutic applications. Antibiotics 9:24. doi: 10.3390/antibiotics9010024

Chen, X., Zhang, L., Wu, Y., Wang, L., Ma, C., Xi, X., et al. (2018). Evaluation of the bioactivity of a mastoparan peptide from wasp venom and of its analogs designed through targeted engineering. Int. J. Biol. Sci. 14, 599-607. doi: 10. 7150/ijbs.23419

Chi, M., Qi, M. A. L., Wang, P., Weir, M. D., Melo, M. A., Sun, X., et al. (2019). Novel bioactive and therapeutic dental polymeric materials to inhibit periodontal pathogens and biofilms. Int. J. Mol. Sci. 20:278. doi: 10.3390/ ijms 20020278

Ch'ng, J.-H., Chong, K. K., Lam, L. N., Wong, J. J., and Kline, K. A. (2019). Biofilm-associated infection by Enterococci. Nat. Rev. Microbiol. 17, 82-94. doi: 10.1038/s41579-018-0107-z

Choi, J. H., Jang, A. Y., Lin, S., Lim, S., Kim, D., Park, K., et al. (2015). Melittin, a honeybee venom-derived antimicrobial peptide, may target methicillinresistant Staphylococcus aureus. Mol. Med. Rep. 12, 6483-6490. doi: 10.3892/ mmr.2015.4275

Ciofu, O., and Tolker-Nielsen, T. (2019). Tolerance and resistance of Pseudomonas aeruginosa biofilms to antimicrobial agents-how $P$. aeruginosa can escape antibiotics. Front. Microbiol. 10:913. doi: 10.3389/fmicb.2019.00913

Ciric, A. D., Petrovic, J. D., Glamoclija, J. M., Smiljkovic, M. S., Nikolic, M. M., Stojkovic, D. S., et al. (2019). Natural products as biofilm formation antagonists and regulators of quorum sensing functions: a comprehensive review update and future trends. South Afr J Bot 120, 65-80. doi: 10.1016/j.sajb.2018.09.010

Costa, B., Mota, R., Tamagnini, P., Martins, M. C. L., and Costa, F. (2020). Natural cyanobacterial polymer-based coating as a preventive strategy to avoid catheter-associated urinary tract infections. Mar. Drugs 18:279. doi: 10.3390/ md18060279

Costerton, J. W., Stewart, P. S., and Greenberg, E. P. (1999). Bacterial biofilms: a common cause of persistent infections. Science 284, 1318-1322. doi: 10.1126/ science.284.5418.1318

Cowan, M. M. (1999). Plant products as antimicrobial agents. Clin. Microbiol. Rev. 12, 564-582. doi: 10.1128/CMR.12.4.564

Cui, T., Bai, F., Sun, M., Lv, X., Li, X., Zhang, D., et al. (2020). Lactobacillus crustorum ZHG 2-1 as novel quorum-quenching bacteria reducing virulence factors and biofilms formation of Pseudomonas aeruginosa. LWT 117:108696. doi: 10.1016/j.lwt.2019.108696

Damodaran, V. B., and Murthy, N. S. (2016). Bio-inspired strategies for designing antifouling biomaterials. Biomater. Res. 20:18. doi: 10.1186/s40824-016-0064-4

Das, M. C., Sandhu, P., Gupta, P., Rudrapaul, P., De, U. C., Tribedi, P., et al. (2016). Attenuation of Pseudomonas aeruginosa biofilm formation by Vitexin: a combinatorial study with azithromycin and gentamicin. Sci Rep. 6, 23347. doi: $10.1038 /$ srep 23347

Dawson, C. C., Intapa, C., and Jabra-Rizk, M. A. (2011). "Persisters": survival at the cellular level. PLoS Pathog. 7:e1002121. doi: 10.1371/journal.ppat.1002121

de Barros, E., Gonçalves, R. M., Cardoso, M. H., Santos, N. C., Franco, O. L., and Candido, E. D. S. (2019). Snake venom cathelicidins as natural antimicrobial peptides. Front. Pharmacol. 10:1415. doi: 10.3389/fphar.2019.01415

De Vos, W. M. (2015). Microbial biofilms and the human intestinal microbiome. NPJ Biofilms Microb. 1:15005. doi: 10.1038/npjbiofilms.2015.5

Deokar, S., and Kadam, D. (2020). An Update on the Management of Urinary Tract Infections in An Era of Drug Resistance: Anti-Biofilm Strategy. Available at SSRN: https://ssrn.com/abstract=3533744 (accessed February 7, 2020).

Dey, P., Parai, D., Banerjee, M., Hossain, S. T., and Mukherjee, S. K. (2020). Naringin sensitizes the anti-biofilm effect of ciprofloxacin and tetracycline against Pseudomonas aeruginosa biofilm. Int. J Med. Microbiol. 310:151410. doi: 10.1016/j.ijmm.2020.151410

Di Somma, A., Moretta, A., Cane, C., Cirillo, A., and Duilio, A. (2020). Antimicrobial and Antibiofilm Peptides. Biomolecules 10:652. doi: 10.3390/ biom 10040652

Diamond, G., Beckloff, N., Weinberg, A., and Kisich, K. O. (2009). The roles of antimicrobial peptides in innate host defense. Curr. Pharm. Des. 15, 2377-2392. doi: 10.2174/138161209788682325

Diaz De Rienzo, M. A., Stevenson, P. S., Marchant, R., and Banat, I. M. (2016) Effect of biosurfactants on Pseudomonas aeruginosa and Staphylococcus aureus biofilms in a bioFlux channel. Appl. Microbiol. Biotechnol. 100, 5773-5779. doi: 10.1007/s00253-016-7310-5

Dieltjens, L., Appermans, K., Lissens, M., Lories, B., Kim, W., Van der Eycken, E. V., et al. (2020). Inhibiting bacterial cooperation is an evolutionarily robust anti-biofilm strategy. Nat. Commun. 11:107. doi: 10.1038/s41467-019-13660-x

Ding, X., Yin, B., Qian, L., Zeng, Z., Yang, Z., Li, H., et al. (2011). Screening for novel quorum-sensing inhibitors to interfere with the formation of Pseudomonas aeruginosa biofilm. J. Med. Microbiol. 60, 1827-1834. doi: 10.1099/jmm.0. 024166-0

Dominguez, E., Zarnowski, R., Sanchez, H., Covelli, A. S., Westler, W. M., Azadi, P., et al. (2018). Conservation and divergence in the Candida species biofilm matrix mannan-glucan complex structure, function, and genetic control. mBio. 9:e00451-18, doi: 10.1128/mBio.00451-18

Eckhart, L., Fischer, H., Barken, K. B., Tolker-Nielsen, T., and Tschachler, E. (2007). DNase1L2 suppresses biofilm formation by Pseudomonas aeruginosa and Staphylococcus aureus. Br. J. Dermat 156, 1342-1345. doi: 10.1111/j.13652133.2007.07886.x

Elshikh, M., Funston, S., Chebbi, A., Ahmed, S., Marchant, R., and Banat, I. M. (2017). Rhamnolipids from non-pathogenic Burkholderia thailandensis E264: physicochemical characterization, antimicrobial and anti-biofilm efficacy against oral hygiene related pathogens. New Biotechnol. 36, 26-36. doi: 10.1016/ j.nbt.2016.12.009

Fenton, M., Keary, R., Mcauliffe, O., O’Mahony, J., and Coffey, A. (2013). Bacteriophage-Derived Peptidase CHAPK eliminates and prevents Staphylococcal Biofilms. Int. J. Microbiol. 2013:625341. doi: 10.1155/2013/625341

Flemming, H.-C. (2011). Biofilm Highlights. Hoboken, NJ: Springer, 81-109.

Flemming, H. C., Neu, T. R., and Wingender, J. (eds) (2016a). The Perfect Slime: Microbial Extracellular Polymeric Substances (EPS). London: IWA publishing. 
Flemming, H. C., and Wingender, J. (2010). The biofilm matrix. Nat. Rev. Microbiol. 8, 623-633. doi: $10.1038 /$ nrmicro2415

Flemming, H.-C., Wingender, J., Szewzyk, U., Steinberg, P., Rice, S. A., and Kjelleberg, S. (2016b). Biofilms: an emergent form of bacterial life. Nat. Rev. Microbiol. 14, 563-575. doi: 10.1038/nrmicro.2016.94

Flemming, H. C., and Wuertz, S. (2019). Bacteria and archaea on Earth and their abundance in biofilms. Nat. Rev. Microbiol. 17, 247-260. doi: 10.1038/s41579019-0158-9

Fletcher, M. M., and Floodgate, G. D. (1973). An electron microscopic demonstration of an acidic polysaccharide involved in the adhesion of a marine bacterium to solid surfaces. J. Gen. Microbiol. 74, 325-334. doi: 10.1099/ 00221287-74-2-325

Fox, E. P., and Nobile, C. J. (2012). A sticky situation: untangling the transcriptional network controlling biofilm development in Candida albicans. Transcription 3, 315-322. doi: 10.4161/trns.22281

Fux, A., Costerton, W., Stewart, P., and Stoodley, P. (2005). Survival strategies of infectious biofilms. Trends Microbiol. 13, 34-40. doi: 10.1016/j.tim.2004.11.010

Gartika, M., Pramesti, H. T., Kurnia, D., and Satari, M. H. (2018). A terpenoid isolated from sarang semut (Myrmecodia pendans) bulb and its potential for the inhibition and eradication of Streptococcus mutans biofilm. BMC Compl. Alt. Med. 18:151. doi: 10.1186/s12906-018-2213-x

Geesey, G. G., Mutch, R., and Costerton, J. W. (1978). Sessile bacteria: an important component of the microbial population in small mountain streams. Limnol. Oceanogr. 23, 1214-1224. doi: 10.4319/lo.1978.23.6.1214

Gharieb, R. M. A., Saad, M. F., Mohamed, A. S., and Tartor, Y. H. (2020). Characterization of two novel lytic bacteriophages for reducing biofilms of zoonotic multidrug-resistant Staphylococcus aureus and controlling their growth in milk. LWT 124:109145. doi: 10.1016/j.lwt.2020.109145

Giordani, B., Costantini, P. E., Fedi, S., Cappelletti, M., Abruzzo, A., Parolin, C., et al. (2019). Liposomes containing biosurfactants isolated from Lactobacillus gasseri exert anti-biofilm activity against methicillin-resistant Staphylococcus aureus strains. Eur. J. Pharm. Biopharm. 139, 246-252. doi: 10.1016/j.ejpb.2019. 04.011

Guilhelmelli, F., Vilela, N., Smidt, K. S., de Oliveira, M. A., da Cunha Morales Álvares, A., Rigonatto, M. C., et al. (2016). Activity of scorpion venom-derived antifungal peptides against planktonic cells of Candida spp. and Cryptococcus neoformans and Candida albicans biofilms. Front. Microbiol. 7:1844. doi: 10. 3389/fmicb.2016.01844

Gunn, J. S., Bakaletz, L. O., and Wozniak, D. J. (2016). What's on the outside matters: the role of the extracellular polymeric substance of gram-negative biofilms in evading host immunity and as a target for therapeutic intervention. J. Biol. Chem. 291, 12538-12546. doi: 10.1074/jbc.R115.707547

Guo, L., Mclean, J. S., Yang, Y., Eckert, R., Kaplan, C. W., Kyme, P., et al. (2015). Precision-guided antimicrobial peptide as a targeted modulator of human microbial ecology. Proc. Natl. Acad. Sci. U.S.A. 112, 7569-7574. doi: 10.1073/ pnas.1506207112

Gutierrez, D., Ruas-Madiedo, P., Martínez, B., Rodríguez, A., and García, P. (2014). Effective removal of staphylococcal biofilms by the endolysin LysH5. PLoS One 9:e107307. doi: 10.1371/journal.pone.0107307

Hall-Stoodley, L., Costerton, J. W., and Stoodley, P. (2004). Bacterial biofilms: from the natural environment to infectious diseases. Nat. Rev. Microbiol. 2, 95-108. doi: $10.1038 /$ nrmicro821

Haque, F., Alfatah, M., Ganesan, K., and Bhattacharyya, M. S. (2016). Inhibitory effect of sophorolipid on Candida albicans biofilm formation and hyphal growth. Sci. Rep. 6:23575. doi: 10.1038/srep23575

Harjai, K., Kumar, R., and Singh, S. (2010). Garlic blocks quorum sensing and attenuates the virulence of Pseudomonas aeruginosa. FEMS Immunol. Med. Microbiol. 58, 161-168. doi: 10.1111/j.1574-695X.2009. 00614.x

Harms, A., Maisonneuve, E., and Gerdes, K. (2016). Mechanisms of bacterial persistence during stress and antibiotic exposure. Science 354, 42-68. doi: 10. $1126 /$ science.aaf 4268

Hell, E., Giske, C. G., Nelson, A., Römling, U., and Marchini, G. (2010). Human cathelicidin peptide LL37 inhibits both attachment capability and biofilm formation of Staphylococcus epidermidis. Lett. Appl. Microbiol. 50, 211-215. doi: $10.1111 / j .1472-765 X .2009 .02778 . x$

Hirt, H., Hall, J. W., Larson, E., and Gorr, S. U. (2018). A D-enantiomer of the antimicrobial peptide GL13K evades antimicrobial resistance in the gram-positive bacteria Enterococcus faecalis and Streptococcus gordonii. PLoS One 13:e0194900. doi: 10.1371/journal.pone.0194900

Hogan, S., Zapotoczna, M., Stevens, N. T., Humphreys, H., O'Gara, J. P., and O'Neill, E. (2017). Potential use of targeted enzymatic agents in the treatment of Staphylococcus aureus biofilm-related infections. J. Hosp. Infect. 96, 177-182. doi: 10.1016/j.jhin.2017.02.008

Ibberson, C. B., Parlet, C. P., Kwiecinski, J., Crosby, H. A., Meyerholz, D. K., and Horswill, A. R. (2016). Hyaluronan modulation impacts Staphylococcus aureus biofilm infection. Inf. Immun. 84, 1917-1929. doi: 10.1128/IAI.014 $18-15$

Izano, E. A., Shah, S. M., and Kaplan, J. B. (2009). Intercellular adhesion and biocide resistance in nontypeable Haemophilus influenzae biofilms. Microb. Pathog. 46, 207-213. doi: 10.1016/j.micpath.2009.01.004

Jakobsen, T. H., van Gennip, M., Phipps, R. K., Shanmugham, M. S., Christensen, L. D., Alhede, M., et al. (2012). Ajoene, a sulfur-rich molecule from garlic, inhibits genes controlled by quorum sensing. Antimicrob. Agents Chemother. 56, 2314-2325. doi: 10.1128/AAC.05919-11

Jakobsen, T. H., Warming, A. N., Vejborg, R. M., Moscoso, J. A., Stegger, M., Lorenzen, F., et al. (2017). A broad range of quorum sensing inhibitor working through sRNA inhibition. Sci. Rep. 7:9857. doi: 10.1038/s41598-017-09886-8

Janeczko, M., Masłyk, M., Kubiński, K., and Golczyk, H. (2017). Emodin, a natural inhibitor of protein kinase CK2, suppresses growth, hyphal development, and biofilm formation of Candida albicans. Yeast 34, 253-265. doi: 10.1002/yea. 3230

Janek, T., Drzymała, K., and Dobrowolski, A. (2020). In vitro efficacy of the lipopeptide biosurfactant surfactin-C15 and its complexes with divalent counterions to inhibit Candida albicans biofilm and hyphal formation. Biofouling 36, 210-221. doi: 10.1080/08927014.2020.1752370

Johari, N. A., Amran, S. S. D., Kamaruzzaman, A. N. A., Man, C. A. I. C., and Yahya, M. F. Z. R. (2020). Anti-biofilm potential and mode of action of malaysian plant species: a review. Sci. Lett. 14, 34-46.

Jones, E. A., McGillivary, G., and Bakaletz, L. O. (2013). Extracellular DNA within a nontypeable Haemophilus influenzae-induced biofilm binds human defensin-3 and reduces its antimicrobial activity. J. Innate Immun. 5, 24-38. doi: 10.1159/ 000339961

Junter, G. A., Thebault, P., and Lebrun, L. (2016). Polysaccharide-based antibiofilm surfaces. Acta Biomater. 30, 13-25. doi: 10.1016/j.actbio.2015.11.010

Kalia, V. C. (2013). Quorum sensing inhibitors: an overview. Biotechnol. Adv. 31 , 224-245. doi: 10.1016/j.biotechadv.2012.10.004

Kalpana, B. J., Aarthy, S., and Pandian, S. K. (2012). Anti-biofilm activity of $\alpha$ amylase from Bacillus subtilis S8-18 against biofilm-forming human bacterial pathogens. Appl. Biochem. Biotechnol. 167, 1778-1794. doi: 10.1007/s12010011-9526-2

Kaplan, J. B., Mlynek, K. D., Hettiarachchi, H., Alamneh, Y. A., Biggemann, L., Zurawski, D. V., et al. (2018). Extracellular polymeric substance (EPS)degrading enzymes reduce staphylococcal surface attachment and biocide resistance on pig skin in vivo. PLoS One 13:e205526. doi: 10.1371/journal.pone. 0205526

Karlapudi, A. P., Venkateswarulu, T. C., Krupanidhi, S., Rohini, K. K., Indira, M., and Vidya, P. K. (2020). Evaluation of anti-cancer, anti-microbial and antibiofilm potential of biosurfactant extracted from an Acinetobacter M6 strain. J. King Saud. Univ. Sci. 32, 223-227. doi: 10.1016/j.jksus.2018.04.007

Karygianni, L., Attin, T., and Thurnheer, T. (2020). Combined DNase and proteinase treatment interferes with composition and structural integrity of multispecies oral biofilms. J. Clin. Med. 9:983. doi: 10.3390/jcm9040983

Kerenga, B. K., McKenna, J. A., Harvey, P. J., Quimbar, P., Garcia, D., Lay, F. T., et al. (2019). Salt-tolerant antifungal and antibacterial activities of the corn defensin ZmD32. Front. Microbiol. 10:795. doi: 10.3389/fmicb.2019.00795

Kerkoub, N., Panda, S. K., Yang, M.-R., Lu, J.-G., Jiang, Z.-H., Nasri, H., et al. (2018). Bioassay-Guided isolation of anti-Candida biofilm compounds from methanol extracts of the aerial parts of Salvia officinalis (Annaba. Algeria). Front. Pharmacol. 9:1418.phar. 2,

Khan, F., Oloketuyi, S. F., and Kim, Y. M. (2019). Diversity of bacteria and bacterial products as anti-biofilm and antiquorum sensing drugs against pathogenic bacteria. Curr. Drug Targets 20, 1156-1179. doi: 10.2174/ 1389450120666190423161249

Khozani, R. S., Shahbazzadeh, D., Harzandi, N., Feizabadi, M. M., and Bagheri, K. P. (2019). Kinetics study of an antimicrobial peptide, melittin, in 
simultaneous biofilm degradation and eradication of potent biofilm-producing MDR Pseudomonas aeruginosa isolates. Int. J. Pept. Res. Ther. 25, 329-338. doi: 10.1007/s10989-018-9675-z

Kipanga, P. N., Liu, M., Panda, S. K., Mai, A. H., Veryser, C., Van Puyvelde, L., et al. (2020). Biofilm inhibiting properties of compounds from the leaves of Warburgia ugandensis Sprague subsp ugandensis against Candida and staphylococcal biofilms. J. Ethnopharmacol. 248:112352. doi: 10.1016/j.jep.2019. 112352

Koo, H., Allan, R. N., Howlin, R. P., Stoodley, P., and Hall-Stoodley, L. (2017). Targeting microbial biofilms: current and prospective therapeutic strategies. Nat. Rev. Microbiol. 15, 740-755. doi: 10.1038/nrmicro.2017.99

Kouakou, K., Panda, S. K., Yang, M.-R., Lu, J.-G., Jiang, Z.-H., Van Puyvelde, L., et al. (2019). Isolation of antimicrobial compounds from Cnestis ferruginea Vahl ex. DC (Connaraceae) leaves through bioassay-guided fractionation. Front. Microbiol. 10:705. doi: 10.3389/fmicb.2019.00705

Kumar, L., Chhibber, S., Kumar, R., Kumar, M., and Harjai, K. (2015). Zingerone silences quorum sensing and attenuates virulence of Pseudomonas aeruginosa. Fitoterapia 102, 84-95. doi: 10.1016/j.fitote.2015.02.002

LaSarre, B., and Federle, M. J. (2013). Exploiting quorum sensing to confuse bacterial pathogens. Microbiol. Mol. Biol. Rev. 77, 73-111. doi: 10.1128/MMBR. 00046- 12

Lee, J.-H., Kim, Y.-G., Ryu, S. Y., Cho, M. H., and Lee, J. (2014a). Ginkgolic acids and Ginkgo biloba extract inhibit Escherichia coli O157: H7 and Staphylococcus aureus biofilm formation. Int. J. Food Microbiol. 174, 47-55. doi: 10.1016/j. ijfoodmicro.2013.12.030

Lee, J.-H., Kim, Y.-G., Ryu, S. Y., Cho, M. H., and Lee, J. (2014b). Resveratrol oligomers inhibit biofilm formation of Escherichia coli O157: H7 and Pseudomonas aeruginosa. J. Nat. Prod. 77, 168-172. doi: 10.1021/np400756g

Lee, J.-H., Regmi, S. C., Kim, J.-A., Cho, M. H., Yun, H., Lee, C.-S., et al. (2011), Apple flavonoid phloretin inhibits Escherichia coli O157: H7 biofilm formation and ameliorates colon inflammation in rats. Infect. Immun. 79, 4819-4827. doi: 10.1128/IAI.05580-11

Lewis, K. (2005). Persister cells and the riddle of biofilm survival. Biochemistry 70, 267-274. doi: 10.1007/s10541-005-0111-6

Lewis, K. (2010). Persister cells. Annu. Rev. Microbiol. 64, 357-372.

Li, M., Xi, X., Ma, C., Chen, X., Zhou, M., Burrows, J. F., et al. (2019). A Novel Dermaseptin isolated from the skin secretion of Phyllomedusa tarsius and its cationicity-enhanced analogue exhibiting effective antimicrobial and anti-proliferative activities. Biomolecules 9:628. doi: 10.3390/biom9100628

Li, Y., Chen, L., Zhang, P., Bhagirath, A. Y., and Duan, K. (2020). ClpV3 of the H3-Type VI Secretion System (H3-T6SS) affects multiple virulence factors in Pseudomonas aeruginosa. Front. Microbiol. 11:1096. doi: 10.3389/fmicb.2020. 01096

Little, B. J., and Lee, J. S. (2015). Microbiologically influenced corrosion: an update. Int. Mat. Rev. 59, 384-393. doi: 10.1179/1743280414Y.3840000000035

Liu, J., Wu, Q., Li, L., Xi, X., Wu, D., Zhou, M., et al. (2017). Discovery of phylloseptins that defense against gram-positive bacteria and inhibit the proliferation of the non-small cell lung cancer cell line, from the skin secretions of Phyllomedusa frogs. Molecules 22:1428. doi: 10.3390/molecules22091428

Loiselle, M., and Anderson, K. W. (2003). The use of cellulase in inhibiting biofilm formation from organisms commonly found on medical implants. Biofouling 19, 77-85. doi: 10.1080/0892701021000030142

Long, L., Chiang, H. Y., and Qian, P. Y. (2020). A potent anti-biofilm agent inhibits and eradicates mono-and multi-species biofilms. bioRxiv[Preprint]. doi: $10.1101 / 2020.03 .25 .009126$

Lu, L., Hu, W., Tian, Z., Yuan, D., Yi, G., Zhou, Y., et al. (2019). Developing natural products as potential anti-biofilm agents. Chin. Med. 14:11. doi: 10. 1186/s13020-019-0232-2

Luo, J., Dong, B., Wang, K., Cai, S., Liu, T., Cheng, X., et al. (2017). Baicalin inhibits biofilm formation, attenuates the quorum sensing-controlled virulence and enhances Pseudomonas aeruginosa clearance in a mouse peritoneal implant infection model. PLoS One 12:e0176883. doi: 10.1371/journal.pone.017 6883

Lyles, J. T., Kim, A., Nelson, K., Bullard-Roberts, A. L., Hajdari, A., Mustafa, B., et al. (2017). The chemical and antibacterial Evaluation of St. John's Wort Oil Macerates Used in Kosovar Traditional Medicine. Front. Microbiol. 8:1639. doi: $10.3389 /$ fmicb.2017.01639
MacKenzie, K. D., Palmer, M. B., Köster, W. L., and White, A. P. (2017). Examining the link between biofilm formation and the ability of pathogenic Salmonella strains to colonize multiple host species. Front. Vet. Sci. 25:138. doi: 10.3389/ fvets.2017.00138

Majik, M. S., Naik, D., Bhat, C., Tilve, S., Tilvi, S., and D'Souza, L. (2013). Synthesis of (R)-norbgugaine and its potential as quorum sensing inhibitor against Pseudomonas aeruginosa. Bioorg. Med. Chem. Lett. 23, 2353-2356. doi: 10.1016/j.bmcl.2013.02.051

Marshall, K. C., Stout, R., and Mitchell, R. (1971). Mechanisms of the initial events in the sorption of marine bacteria to surfaces. J. Gen. Microbiol. 68, 337-348. doi: 10.1099/00221287-68-3-337

Mitchell, K. F., Zarnowski, R., Sanchez, H., Edward, J. A., Reinicke, E. L., Nett, J. E., et al. (2015). Community participation in biofilm matrix assembly and function. Proc. Natl. Acad. Sci. U.S.A. 112, 4092-4097. doi: 10.1073/pnas.1421437112

Mohammadi, M., Taheri, B., Momenzadeh, N., Salarinia, R., Nabipour, I., Farshadzadeh, Z., et al. (2018). Identification and characterization of novel antimicrobial peptide from hippocampus comes by In Silico and experimental studies. Mar. Biotechnol. 20, 718-728. doi: 10.1007/s10126-018-9843-3

Mookherjee, N., Brown, K. L., Bowdish, D. M., Doria, S., Falsafi, R., Hokamp, K., et al. (2006). Modulation of the TLR-mediated inflammatory response by the endogenous human host defense peptide LL-37. J. Immunol. 176, 2455-2464. doi: 10.4049/jimmunol.176.4.2455

Murata, R. M., Branco-de-Almeida, L. S., Franco, E. M., Yatsuda, R., dos Santos, M. H., de Alencar, S. M., et al. (2010). Inhibition of Streptococcus mutans biofilm accumulation and development of dental caries in vivo by 7 -epiclusianone and fluoride. Biofouling 26, 865-872. doi: 10.1080/08927014.2010.52 7435

Nahar, S., Mizan, M. F. R., Ha, A. J. W., and Ha, S. D. (2018). Advances and future prospects of enzyme-based biofilm prevention approaches in the food industry. Compr. Rev. Food Sci. Food Saf. 17, 1484-1502. doi: 10.1111/1541-4337.12382

Nguyen, B. V., Nagakubo, T., Toyofuku, M., Nomura, N., and Utada, A. S. (2020). Synergy between Sophorolipid biosurfactant and SDS increases the efficiency of $P$. aeruginosa biofilm disruption. Langmuir 36, 6411-6420. doi: 10.1021/acs. langmuir.0c00643

Ohadi, M., Forootanfar, H., Dehghannoudeh, G., Eslaminejad, T., Ameri, A., Shakibaie, M., et al. (2020). Antimicrobial, anti-biofilm, and anti-proliferative activities of lipopeptide biosurfactant produced by Acinetobacter junii B6. Microb. Pathog. 138:103806. doi: 10.1016/j.micpath.2019.103806

Olwal, C. O., Ang'ienda, P. O., and Ochiel, D. O. (2019). Alternative sigma factor $\mathrm{B}(\sigma \mathrm{B})$ and catalase enzyme contribute to Staphylococcus epidermidis biofilm's tolerance against physico-chemical disinfection. Sci. Rep. 9:5355. doi: 10.1038/ s41598-019-41797-8

Padhi, A., Naik, S. K., Sengupta, S., Ganguli, G., and Sonawane, A. (2016). Expression of Mycobacterium tuberculosis NLPC/p60 family protein Rv0024 induce biofilm formation and resistance against cell wall acting antituberculosis drugs in Mycobacterium smegmatis. Microbe Infect. 18, 224-236. doi: 10.1016/j.micinf.2015.11.007

Paluch, E., Rewak-Soroczynska, J., Jẹdrusik, I., Mazurkiewicz, E., and Jermakow, K. (2020). Prevention of biofilm formation by quorum quenching. Appl. Microbiol. Biotechnol. 104, 1871-1881. doi: 10.1007/s00253-020-10349-w

Pan, C., Zubin, Z., and Xiaowei, Y. (2018). Coatings as the useful drug delivery system for the prevention of implant-related infections. J Orthop. Sur. Res. 13:220. doi: 10.1186/s13018-018-0930-y

Panda, S. K., Das, R., Lavigne, R., and Luyten, W. (2020). Indian medicinal plant extracts to control multidrug-resistant $S$. aureus, including in biofilms. South Afr. J. Bot. 128, 283-291. doi: 10.1016/j.sajb.2019.11.019

Paraszkiewicz, K., Moryl, M., Płaza, G., Bhagat, D. K., Satpute, S., and Bernat, P. (2019). Surfactants of microbial origin as anti-biofilm agents. Int. J. Environ. Health Res. 11, 1-20. doi: 10.1080/09603123.2019.1664729

Parducho, K. R., Beadell, B., Ybarra, T., Bush, M., Escalera, E., Mendez, M., et al. (2020). The antimicrobial peptide human beta-defensin 2 inhibits biofilm production of Pseudomonas aeruginosa without compromising metabolic activity. Front. Immunol. 11:805. doi: 10.3389/fimmu.2020.00805

Payne, D. E., Martin, N. R., Parzych, K. R., Rickard, A. H., Underwood, A., and Boles, B. R. (2013). Tannic acid inhibits Staphylococcus aureus surface colonization in an IsaA-dependent manner. Infect. Immun. 81, 496-504. doi: 10.1128/IAI.00877-12 
Peng, X., Zhu, L., Wang, Z., and Zhan, X. (2020). Enhanced stability of the bactericidal activity of nisin through conjugation with gellan gum. Int. J. Biol. Macromol. 148, 525-532. doi: 10.1016/j.ijbiomac.2020.01.164

Pires, D. P., Costa, A. R., Pinto, G., Meneses, L., and Azeredo, J. (2020). Current challenges and future opportunities of phage therapy. FEMS Microbiol. Rev. fuaa017. doi: 10.1093/femsre/fuaa017

Pletzer, D., Coleman, S. R., and Hancock, R. E. (2016). Anti-biofilm peptides as a new weapon in antimicrobial warfare. Curr. Opin. Microbiol. 33, 35-40. doi: 10.1016/j.mib.2016.05.016

Qian, W., Zhang, J., Wang, W., Liu, M., Fu, Y., Li, X., et al. (2020). Efficacy of chelerythrine against mono- and dual-species biofilms of Candida albicans and Staphylococcus aureus and its properties of inducing hypha-to-yeast transition of C. albicans. J. Fungi 6:45. doi: 10.3390/jof6020045

Qvortrup, K., Hultqvist, L., Nilsson, M., Jakobsen, T. H., Jansen, C. U., Uhd, J., et al. (2019). Small molecule anti-biofilm agents developed on the basis of mechanistic understanding of biofilm formation. Front. Chem. 7:742. doi: 10.3389/fchem.2019.00742

Rajasekharan, S. K., and Ramesh, S. (2013). Cellulase inhibits Burkholderia cepacia biofilms on diverse prosthetic materials. Pol. J. Microbiol. 62, 327-330.

Rajput, A., and Kumar, M. (2018). Anti-Biofilm Peptides: A New Class of Quorum Quenchers and Their Prospective Therapeutic Applications: Biotechnological Applications of Quorum Sensing Inhibitors. Singapore: Springer, 87-110. doi: 10.1007/978-981-10-9026-4_5

Raorane, C. J., Lee, J. H., Kim, Y. G., Rajasekharan, S. K., Garcia-Contreras, R., and Lee, J. (2019). Antibiofilm and Antivirulence Efficacies of Flavonoids and Curcumin Against Acinetobacter baumannii. Front. Microbiol. 10:990. doi: 10. 3389/fmicb.2019.00990

Razak, F. A., and Rahim, Z. H. (2003). The anti-adherence effect of Piper betle and Psidium guajava extracts on the adhesion of early settlers in dental plaque to saliva-coated glass surfaces. J. Oral Sci. 45, 201-206. doi: 10.2334/josnusd.45. 201

Reuter, M., and Kruger, D. H. (2020). Approaches to optimize therapeutic bacteriophage and bacteriophage-derived products to combat bacterial infections. Virus Genes 56, 136-149. doi: 10.1007/s11262-020-01735-7

Roy, R., Tiwari, M., Donelli, G., and Tiwari, V. (2018). Strategies for combating bacterial biofilms: a focus on anti-biofilm agents and their mechanisms of action. Virulence 9, 522-554. doi: 10.1080/21505594.2017.1313372

Sacco, L. P., Castellane, T. C. L., Polachini, T. C., de Macedo Lemos, E. G., and Alves, L. M. C. (2019). Exopolysaccharides produced by Pandoraea shows emulsifying and anti-biofilm activities. J. Polym. Res. 26, 91. doi: 10.1007/ s10965-019-1737-1

Samoilova, Z., Smirnova, G., and Oktyabrsky, O. (2019a). The effect of catechin, tannic and gallic acids on biofilm formation in Escherichia coli depends on medium composition. Asian J. Microbiol. Biotechnol. 4, 16-23.

Samoilova, Z., Tyulenev, A., Muzyka, N., Smirnova, G., and Oktyabrsky, O. (2019b). Tannic and gallic acids alter redox-parameters of the medium and modulate biofilm formation. AIMS Microbiol. 5, 379-392. doi: 10.3934/ microbiol.2019.4.379

Sandasi, M., Leonard, C. M., and Viljoen, A. M. (2010). The in-vitro antibiofilm activity of selected culinary herbs and medicinal plants against Listeria monocytogenes. Lett. Appl. Microbiol. 50, 30-35. doi: 10.1111/j.1472-765X.2009. 02747.xLAM 2747

Sardi, J. C., Freires, I. A., Lazarini, J. G., Infante, J., de Alencar, S. M., and Rosalen, P. L. (2017). Unexplored endemic fruit species from Brazil: antibiofilm properties, insights into mode of action, and systemic toxicity of four Eugenia spp. Microb. Pathog. 105, 280-287. doi: 10.1016/j.micpath.2017.02.044

Satpute, S. K., Banpurkar, A. G., Banat, I. M., Sangshetti, J. N., Patil, R. H., and Gade, W. N. (2016). Multiple roles of biosurfactants in biofilms. Curr. Pharm. Des. 22, 1429-1448. doi: 10.2174/1381612822666160120152704

Satpute, S. K., Mone, N. S., Das, P., Banat, I. M., and Banpurkar, A. G. (2019). Inhibition of pathogenic bacterial biofilms on PDMS based implants by L. acidophilus derived biosurfactant. BMC Microbiol. 19:39. doi: 10.1186/ s12866-019-1412-z

Scoffone, V. C., Trespidi, G., Chiarelli, L. R., Barbieri, G., and Buroni, S. (2019). Quorum sensing as antivirulence target in cystic fibrosis pathogens. Int. J. Mol. Sci. 20:1838. doi: 10.3390/ijms20081838

Seneviratne, C. J., Suriyanarayanan, T., Swarup, S., Chia, K. H. B., Nagarajan, N., and Zhang, C. (2017). Transcriptomics analysis reveals putative genes involved in biofilm formation and biofilm-associated drug resistance of Enterococcus faecalis. J. Endodont. 43, 949-955. doi: 10.1016/j.joen.2017.01.020

Shahrour, H., Ferrer-Espada, R., Dandache, I., Barcena-Varela, S., Sanchez-Gomez, S., Chokr, A., et al. (2019). AMPs as anti-biofilm agents for human therapy and prophylaxis. Adv. Exp. Med. Biol. 1117, 257-279. doi: 10.1007/978-981-133588-4_14

Sharahi, J. Y., Azimi, T., Shariati, A., Safari, H., Tehrani, M. K., and Hashemi, A. (2019). Advanced strategies for combating bacterial biofilms. J. Cell Physiol. 234, 14689-14708. doi: 10.1002/jcp.28225

Sharma, D., and Bisht, G. S. (2020). Recent updates on antifungal peptides. Mini Rev. Med. Chem. 20, 260-268. doi: 10.2174/1389557519666190926112423

Shastry, R. P., Rekha, P. D., and Rai, V. R. (2019). Biofilm inhibitory activity of metalloprotein AHL-lactonase from the cell-free lysate of endophytic Enterobacter species isolated from Coscinium fenestratum Gaertn. Biocat. Agri. Biotechnol. 18:101009. doi: 10.1016/j.bcab.2019.01.047

Shehabeldine, A. M., Ashour, R. M., Okba, M. M., and Saber, F. R. (2020). Callistemon citrinus bioactive metabolites as new inhibitors of methicillinresistant Staphylococcus aureus biofilm formation. J. Ethnopharmacol. 254, 112669. doi: 10.1016/j.jep.2020.112669

Shin, J. M., Gwak, J. W., Kamarajan, P., Fenno, J. C., Rickard, A. H., and Kapila, Y. L. (2016). Biomedical applications of Nisin. J. Appl. Microbiol. 120, 14491465. doi: $10.1111 /$ jam. 13033

Singh, S., Singh, S. K., Chowdhury, I., and Singh, R. (2017). Understanding the mechanism of bacterial biofilms resistance to antimicrobial agents. Open Microbiol. J. 11, 53-62. doi: 10.2174/1874285801711010053

Soares, A., Roussel, V., Pestel-Caron, M., Barreau, M., Caron, F., Bouffartigues, E., et al. (2019). Understanding ciprofloxacin failure in Pseudomonas aeruginosa biofilm: persister cells survive matrix disruption. Front. Microbiol. 10:2603. doi: $10.3389 /$ fmicb. 2019.02603

Spormann, A. M. (2008). Physiology of microbes in biofilms. Curr. Top. Microbiol. Immunol. 322, 17-36. doi: 10.1007/978-3-540-75418-3_2

Srinivasan, R., Devi, K. R., Kannappan, A., Pandian, S. K., and Ravi, A. V. (2016). Piper betle and its bioactive metabolite phytol mitigates quorum sensing mediated virulence factors and biofilm of nosocomial pathogen Serratia marcescens in vitro. J. Ethnopharmacol. 193, 592-603. doi: 10.1016/j.jep.2016. 10.017

Steinstraesser, L., Tack, B. F., Waring, A. J., Hong, T., Boo, L. M., Fan, M. H., et al. (2002). Activity of novispirin G10 against Pseudomonas aeruginosa in vitro and infected burns. Antimicrob. Agents Chemother. 46, 1837-1844. doi: 10.1128/ AAC.46.6.1837-1844.2002

Stewart, P. S., and Franklin, M. J. (2008). Physiological heterogeneity in biofilms. Nat. Rev. Microbiol. 6, 199-210. doi: 10.1038/nrmicro1838

Sugimoto, S., Iwamoto, T., Takada, K., Okuda, K. I., Tajima, A., Iwase, T., et al. (2013). Staphylococcus epidermidis Esp degrades specific proteins associated with Staphylococcus aureus biofilm formation and host-pathogen interaction. J. Bacteriol. 195, 1645-1655. doi: 10.1128/JB.01672-12

Sztukowska, M. N., Roky, M., and Demuth, D. R. (2019). Peptide and non-peptide mimetics as potential therapeutics targeting oral bacteria and oral biofilms. Mol. Oral Microbiol. 34, 169-182. doi: 10.1111/omi.12267

Tabak, M., Scher, K., Chikindas, M. L., and Yaron, S. (2009). The synergistic activity of triclosan and ciprofloxacin on biofilms of Salmonella Typhimurium. FEMS Microbiol. Lett. 301, 69-76. doi: 10.1111/j.1574-6968.2009. 01804.x

Tahrioui, A., Ortiz, S., Azuama, O. C., Bouffartigues, E., Benalia, N., Tortuel, D., et al. (2020). Membrane-Interactive Compounds From Pistacia lentiscus L. Thwart Pseudomonas aeruginosa Virulence. Front. Microbiol. 11:1068. doi: 10.3389/fmicb.2020.01068

Tan, Y., Leonhard, M., Moser, D., and Schneider-Stickler, B. (2017). Inhibition activity of Lactobacilli supernatant against fungal-bacterial multispecies biofilms on silicone. Microb Pathog. 113, 197-201. doi: 10.1016/j.micpath.2017. 10.051

Tapia-Rodriguez, M. R., Bernal-Mercado, A. T., Gutierrez-Pacheco, M. M., Vazquez-Armenta, F. J., Hernandez-Mendoza, A., Gonzalez-Aguilar, G. A., et al. (2019). Virulence of Pseudomonas aeruginosa exposed to carvacrol: alterations of the Quorum sensing at enzymatic and gene levels. J. Cell Commun. Signal. 13, 531-537. doi: 10.1007/s12079-019-00516-8

Tjabringa, G. S., Ninaber, D. K., Drijfhout, J. W., Rabe, K. F., and Hiemstra, P. S. (2006). Human cathelicidin LL-37 is a chemoattractant for eosinophils and 
neutrophils that acts via formyl-peptide receptors. Int. Arch. Allergy Immunol. 140, 103-112. doi: 10.1159/000092305

Trentin, D. S., Giordani, R. B., Zimmer, K. R., da Silva, A. G., da Silva, M. V., dos Santos, et al. (2011). Potential of medicinal plants from the Brazilian semiarid region Caatinga) against Staphylococcus epidermidis planktonic and biofilm lifestyles. J. Ethnopharmacol. 137, 327-335. doi: 10.1016/j.jep.2011.05.030

Tseng, B. S., Zhang, W., Harrison, J. J., Quach, T. P., Song, J. L., Penterman, J., et al. (2013). The extracellular matrix protects Pseudomonas aeruginosa biofilms by limiting the penetration of tobramycin. Environ. Microbiol. 15, 2865-2878. doi: 10.1111/1462-2920.12155

Tursi, S. A., Puligedda, R. D., Szabo, P., Nicastro, L. K., Miller, A. L., Qiu, C., et al. (2020). Salmonella Typhimurium biofilm disruption by a human antibody that binds a pan-amyloid epitope on curli. Nat. Commun. 11, 1-13. doi: 10.1038/ s41467-020-14685-3

Uppuluri, P., Zaldivar, M. A., Anderson, M. Z., Dunn, M. J., Berman, J., Ribot, J. L. L., et al. (2018). Candida albicans dispersed cells are developmentally distinct from the biofilm and planktonic cells. mBio 9:e001338-18. doi: 10.1128/ mBio.01338- 18

Van der Veen, S., and Abee, T. (2011). Mixed species biofilms of Listeria monocytogenes and Lactobacillus plantarum show enhanced resistance to benzalkonium chloride and peracetic acid. Int. J. Food Microbiol. 144, 421-431. doi: 10.1016/j.ijfoodmicro.2010.10.029

Vasilchenko, A. S., and Rogozhin, E. A. (2019). Sub-Inhibitory effects of antimicrobial peptides. Front. Microbiol. 10:1160. doi: 10.3389/fmicb.2019. 01160

Vijayakumar, K., and Ramanathan, T. (2020). Musa acuminata and its bioactive metabolite 5-Hydroxymethylfurfural mitigates quorum sensing (las and rhl) mediated biofilm and virulence production of nosocomial pathogen Pseudomonas aeruginosa in vitro. J. Ethnopharmacol. 246:112242. doi: 10.1016/ j.jep.2019.112242

Vikram, A., Jayaprakasha, G. K., Uckoo, R. M., and Patil, B. S. (2013). Inhibition of Escherichia coli O157: H7 motility and biofilm by $\beta$-sitosterol glucoside. Biochim. Biophys. Acta Gen. Subj. 1830, 5219-5228. doi: 10.1016/j.bbagen.2013. 07.022

Vikram, A., Jesudhasan, P., Pillai, S., and Patil, B. (2012). Isolimonic acid interferes with Escherichia coli O157: H7 biofilm and TTSS in QseBC and QseA dependent fashion. BMC Microbiol. 12:261. doi: 10.1186/1471-2180-12-261

Vikram, A., Jesudhasan, P. R., Jayaprakasha, G. K., Pillai, S. D., and Patil, B. S. (2011). Citrus limonoids interfere with Vibrio harveyi cell-cell signalling and biofilm formation by modulating the response regulator LuxO. Microbiol. 157(Pt. 1), 99-110. doi: 10.1099/mic.0.041228-0

Von Borowski, R. G., Sophie, C. H. A. T., Schneider, R., Giudice, E., Zimmer, A. R., Gnoatto, S. C. B., et al. (2020). Capsicumine: a new peptide from red peppers turns out to be a powerful anti-biofilm agent and displays a new mechanism of action, matrix anti-assembly. bioRxiv[Preprint] doi: 10.1101/2020.04.03.022020

Wang, T., Huang, W., Duan, Q., Wang, J., Cheng, H., Shao, J., et al. (2019). Sodium houttuyfonate in vitro inhibits biofilm dispersion and expression of bdlA in Pseudomonas aeruginosa. Mol. Biol. Rep. 46, 471-477. doi: 10.1007/s11033-0184497-9

Wilkins, M., Hall-Stoodley, L., Allan, R. N., and Faust, S. N. (2014). New approaches to the treatment of biofilm-related infections. J. Infect. 69, S47-S52. doi: 10.1016/j.jinf.2014.07.014

Wingender, J., and Flemming, H.-C. (2011). Biofilms in drinking water and their role as a reservoir for pathogens. Int. J. Hyg. Environ. Health 214, 417-423. doi: 10.1016/j.ijheh.2011.05.009

Xiang, H., Cao, F., Ming, D., Zheng, Y., Dong, X., Zhong, X., et al. (2017). Aloe-emodin inhibits Staphylococcus aureus biofilms and extracellular protein production at the initial adhesion stage of biofilm development. Appl. Microbiol. Biotechnol. 101, 6671-6681. doi: 10.1007/s00253-017-8403-5

Xu, L., Shao, C., Li, G., Shan, A., Chou, S., Wang, J., et al. (2020). Conversion of broad-spectrum antimicrobial peptides into species-specific antimicrobials capable of precisely targeting pathogenic bacteria. Sci. Rep. 10:944. doi: 10.1038/ s41598-020-58014-6

Xu, Z., Zhang, H., Yu, H., Dai, Q., Xiong, J., Sheng, H., et al. (2019). Allicin inhibits Pseudomonas aeruginosa virulence by suppressing the rhl and pqs quorum-sensing systems. Can. J. Microbiol. 65, 563-574.

Yan, X., Gu, S., Cui, X., Shi, Y., Wen, S., Chen, H., et al. (2019). Antimicrobial, anti-adhesive and anti-biofilm potential of biosurfactants isolated from Pediococcus acidilactici and Lactobacillus plantarum against Staphylococcus aureus CMCC26003. Microb. Pathog. 127, 12-20. doi: 10.1016/j.micpath.2018. 11.039

Yan, X., Gu, S., Shi, Y., Cui, X., Wen, S., and Ge, J. (2017). The effect of emodin on Staphylococcus aureus strains in planktonic form and biofilm formation in vitro. Arch. Microbiol. 199, 1267-1275. doi: 10.1007/s00203-0171396-8

Yang, Y. B., Wang, S., Wang, C., Huang, Q. Y., Bai, J. W., Chen, J. Q., et al. (2015). Emodin affects biofilm formation and expression of virulence factors in Streptococcus suis ATCC700794. Arch. Microbiol. 197, 1173-1180. doi: 10.1007/ s00203-015-1158-4

Yong, Y. Y., Dykes, G. A., and Choo, W. S. (2019). Biofilm formation by staphylococci in health-related environments and recent reports on their control using natural compounds. Crit. Rev. Microbiol. 45, 201-222. doi: 10. 1080/1040841X.2019.1573802

Yuan, L., Hansen, M. F., Roder, H. L., Wang, N., Burmolle, M., and He, G. (2020). Mixed-species biofilms in the food industry: current knowledge and novel control strategies. Crit. Rev. Food Sci. Nutr. 60, 2277-2293. doi: 10.1080/ 10408398.2019.1632790

Yuan, Y., Zai, Y., Xi, X., Ma, C., Wang, L., Zhou, M., et al. (2019). A novel membrane-disruptive antimicrobial peptide from frog skin secretion against cystic fibrosis isolates and evaluation of anti-MRSA effect using Galleria mellonella model. Biochim. Biophys. Acta Gen. Subj. 1863, 849-856. doi: 10. 1016/j.bbagen.2019.02.013

Zarnowski, R., Sanchez, H., Covelli, A. S., Dominguez, E., Jaromin, A., Berhardt, J., et al. (2018). Candida albicans biofilm-induced vesicles confer drug resistance through matrix biogenesis. PLoS Biol. 16:e2006872. doi: 10.1371/journal.pbio. 2006872

Zhang, L., Liang, E., Cheng, Y., Mahmood, T., Ge, F., Zhou, K., et al. (2020). Is combined medication with natural medicine a promising therapy for bacterial biofilm infection? Biomed. Pharmacother. 128:110184. doi: 10.1016/j.biopha. 2020.110184

Zhong, L., Ravichandran, V., Zhang, N., Wang, H., Bian, X., Zhang, Y., et al. (2020). Attenuation of Pseudomonas aeruginosa quorum sensing by natural products: virtual screening, evaluation and biomolecular interactions. Int. J. Mol. Sci. 21:2190. doi: 10.3390/ijms21062190

Zhou, J. W., Luo, H. Z., Jiang, H., Jian, T. K., Chen, Z. Q., and Jia, A. Q. (2018). Hordenine: a novel quorum sensing inhibitor and antibiofilm agent against Pseudomonas aeruginosa. J Agri. Food Chem. 66, 1620-1628. doi: 10.1021/acs. jafc.7b05035

Conflict of Interest: The authors declare that the research was conducted in the absence of any commercial or financial relationships that could be construed as a potential conflict of interest.

Copyright (c) 2020 Mishra, Panda, De Mandal, Shakeel, Bisht and Khan. This is an open-access article distributed under the terms of the Creative Commons Attribution License (CC BY). The use, distribution or reproduction in other forums is permitted, provided the original author(s) and the copyright owner(s) are credited and that the original publication in this journal is cited, in accordance with accepted academic practice. No use, distribution or reproduction is permitted which does not comply with these terms. 